\title{
An online platform to unify and synchronise heritage architecture information
}

Authors: Isabel Jordán Palomar, Jorge L. García Valldecabres, Patricia Tzortzopoulos, Eugenio Pellicer.

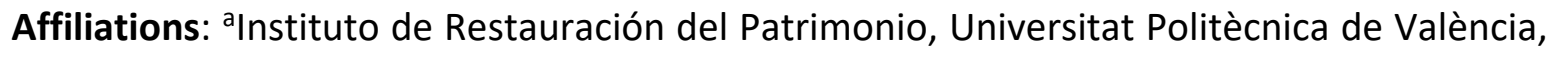
Valencia, Spain; 'braphic Expression Department, Universitat Politècnica de València, Valencia, Spain; 'School of Art, Design and Architecture, University of Huddersfield, Huddersfield, United Kingdom; dSchool of Civil Engineering, Universitat Politècnica de València, Valencia, Spain.

Contact email: isjorpa@upvnet.upv.es

\section{Abstract}

Traditionally, in heritage architecture, each discipline works independently, generating dispersed data. Heritage Building Information Modelling (HBIM) can provide benefits in managing heritage projects. However, the modelling task is laborious, BIM software tends to be complex, and historical databases are not synchronised with HBIM models. The aim of this research is to create an online work platform where interdisciplinary stakeholders can synchronise heritage information. Design Science Research (DSR) was the methodological approach adopted, consisting of designing an artefact and evaluating it iteratively. As a result, an innovative in-cloud system named BIMlegacy that connects the intrinsic HBIM database with heritage documentary databases was designed. BIMlegacy was used to manage a complete heritage registration project in a case study. The results were validated through a focus group with external professionals. The theoretical definition of the BIMlegacy platform structure is a contribution to knowledge as it could be used as a basis to develop new systems. BIMlegacy allows non-technical heritage stakeholders to collaborate effectively, which is a notable practical contribution.

\section{Introduction: Heritage architecture challenges}

"A Heritage asset is a building, monument, site, place, area or landscape identified as having a degree of significance meriting consideration in planning decisions, because of its heritage interest" (Department for Communities and Local Government of United Kingdom, 2012). The main difference between new buildings and heritage buildings is that the latter need to be documented due to their architectonic and cultural values that represent society's common heritage (Gazzola et al., 1964). Heritage projects require historic, archaeological, and artistic documentation, as well as a study of the sociocultural heritage setting (Naeyer et al., 2000). 
Heritage stakeholders (e.g. archaeologists, archivists, structural engineers or restorers) usually work separately, which means that dispersed data is produced (Garagnani et al., 2016), duplicated information is generated (Migilinskas et al., 2013), and other stakeholders' contributions are sometimes not taken into consideration (González-Varas Ibáñez, 1999). For instance, the archaeologist may research stone pathologies without considering the architect's previous report. These unproductive work practices cause distrust of historic project management and uncertainties in costs and schedules for property developers (Teo and Loosemore, 2001).

Inefficiencies in heritage architecture interventions - conservation, rehabilitation, restoration and reconstruction - cause the conservation of heritage buildings to be costly and tend to compromise the preservation of their cultural values (Kempton, 2006). The need for new systems to manage heritage interventions is further highlighted by the fact that there is an increasing number of heritage buildings needing restoration work in cities across Europe. Interventions in existing buildings represent a high percentage in the total construction industry. For instance, in Spain refurbishments represented $55.7 \%$ of the total construction sector in 2016 according to the Ministry of Economy Competitiveness.

Therefore, this research aims to develop a system that enables the connection of three-dimensional HBIM models and heritage documentary databases to allow non-technical heritage stakeholders who do not use BIM software (e.g. historians, restorers, monument managers, etc.) to collaborate effectively with the technical stakeholders (e.g. architects, engineers or archaeologists). The objectives of this study are: (1) to design an online platform that unifies HBIM databases with documentary databases and broadcasts the cultural legacy of monuments; (2) to implement the designed platform to the San Juan del Hospital case study; (3) to evaluate the quality of the platform through a focus group with interdisciplinary heritage stakeholders and BIM experts.

In order to achieve these objectives, this paper is organised as follows. Initially, a literature synthesis is presented, followed by a description and justification of the research method adopted in the work. Following this, the BIMlegacy platform development and implementation in a case study are discussed. Finally, the partial validation of the platform through a focus group, discussion and conclusions are presented.

\subsection{HBIM}

HBIM has emerged as a suitable system to solve some of the current inefficiencies in the heritage architecture sector. Murphy has defined HBIM as a new system of modelling historic structures creating full 2D and 3D models, which include details under the surface of the object concerning its methods of construction and material makeup (Murphy et al., 2009). HBIM is a broad term that includes historical data, conservation policies and significance values (Arayici et al., 2017). Volk (2014) affirmed that BIM in existing buildings needs improvements in conversion point clouds to BIM models and modelling complex historic structures (Volk et al., 2014). Dore and Murphy (2017) stated the categories within the HBIM state of the art: heritage documentation standards, data collection and pre-processing techniques, 3D modelling concepts, as built BIM, and procedural modelling (Dore and Murphy, 2017). 
The claimed HBIM advantages to manage heritage interventions are described as:

- The intrinsic database that the computerised BIM systems have allows the synchronisation of information in real time (Quattrini et al., 2015).

- The capability to represent the historic phases in an integrated way.

- The creation of libraries of historic items designed from historic manuscripts and architectural pattern books (Antonopoulou and Bryan, 2017). This will help HBIM modellers to perform their work faster and more accurately as they could reuse families from libraries.

- The generation of efficiency simulations (Oreni et al., 2014). This can improve the quality of the project and its energy behaviour.

- HBIM can help reduce errors as information can be updated in real time and data can be synchronised, reducing the potential of human error (Brumana et al., 2013).

Even though HBIM has advantages, there are a series of heritage challenges that simple HBIM could not solve and that require a HBIM platform to converge all data (Volk et al., 2014). To date, HBIM has been used mainly for maintenance and large refurbishments, and its use for heritage buildings is scarce (Arayici et al., 2017). Existing results of HBIM case studies discuss issues related to the difficulty in modelling complex architecture with HBIM, difficulties in correctly documenting historic buildings, and challenges in the active participation of all interdisciplinary stakeholders (Garagnani et al., 2016).

Modelling historic structures tends to be laborious, difficult, and time consuming due to the lack of BIM knowledge of heritage stakeholders and the complex characteristic of historic buildings (Barazzetti et al., 2015). On one hand, historians, restorers, and monument managers tend not to possess technical training, which makes BIM modelling very difficult for them; thus, they cannot fully participate within the HBIM process. This issue could be solved by using a system that synchronises non-technical stakeholders' work with HBIM models. Furthermore, historic buildings have an extended time of use that usually alters some of their features, e.g. repurposed structures, reused materials, and shape variations. Historic buildings usually include a diversity of fabrics, several historic-constructive phases and, sometimes, pathologies such as cracks or humidity (Green and Dixon, 2016).

The literature demonstrates that HBIM does not yet fully contemplate the historical and cultural legacy of the buildings and sites (Ilter and Ergen, 2015). Most HBIM publications focus on modelling, disregarding the documentation processes. This is mainly due to the fact that historians and archivists, who usually perform the documentation in heritage projects, do not have the ability to manipulate HBIM models (Dore and Murphy, 2017). Hence, the creation of a system to support their participation in the process is important.

Heritage stakeholders have different needs from those of general Architecture, Engineering and Construction (AEC) professionals, and these differences need to be considered (Megahed, 2015). Furthermore, HBIM studies tend to focus on the architect's point of view with not enough consideration of other stakeholders' needs. For example, an archaeologist may require tools to re-create volumes that have previously dispersed within a heritage project (Garagnani et al., 2016). An investigation of heritage stakeholders' needs is required, including an understanding of their workflows and the systems that they currently use. Heritage organisations and government institutions promote investigations to solve those 
HBIM issues (Perng et al., 2007). International framework programmes, such as the Horizon 2020European Commission, architectural regulations, and different international conservation councils, are promoting collaborative systems to enable better information sharing in heritage projects, as well as more cultural diffusion within society (Arayici et al., 2017).

HBIM involves multiple stakeholders that usually work in different geographic locations, which makes collaboration challenging. Therefore, different authors have suggested that a possible solution would be the creation of a Common Data Environment (CDE) to synchronise information in real time (Du et al., 2018; Li et al., 2018; Salvador García et al., 2018; Oreni et al., 2014). The CDE is discussed in the next session.

\subsection{Common Data Environment}

The concept of the CDE specifies a single source of information for the project, that is used to collect, manage and disseminate project information through strictly controlled processes (Antonopoulou and Bryan, 2017). It is a tool that allows a transparent and controllable process (Building SMART Spanish Chapter, 2014). CDE aims to allow interdisciplinary collaboration in the BIM environment (Afsari et al., 2016). A CDE could be a project server, an extranet, or a cloud-based system (Arthur et al., 2017). The success of the CDE depends on the BIM infrastructure, i.e. software, hardware and networks. Furthermore, a protocol of use must be in place and strictly adhered to by all members of the project team to ensure information consistency and quality (Antonopoulou and Bryan, 2017). The benefits of using CDE are the possibility to work with people who are geographically separated, the immediacy of access to the information, the possibility to order and filter different layers of information, and the possibility to control the permits (Camarinha-Matos et al., 2017).

BIM platforms began due to the need for interoperability and synchronisation. Grillo and JardimGoncalves (2009) described that the use of BIM as a central repository for building project information could revolutionise information management for a project and throughout its life cycle; the same authors proposed BIM e-platforms for the exchange of technical data and BIM models (Grilo and JardimGoncalves, 2010). Online platforms among BIM are a single source of information to collect, manage and disseminate graphical and non-graphical information (Standard I. S.O., 2010).

BIM platforms hosted in the cloud are a common topic of study both between scientists and BIM software companies. Latency and the real-time synchronisation of BIM data for collaborative decisionmaking is an important practical matter (Du et al., 2018). Latency articulates the functioning of any platform and it should be taken into account when designing any kind of CDE. BIM platforms are emerging that aim to solve the needs of different architecture areas. Results of BIM case studies where CDE was used as central repository have been, in general, successful. The most relevant studies are described as follows.

Pergn et al. (2007) were pioneer investigators of CDE solutions, designing a system to assist contractors in building core competencies as well as sustaining competitive advantages. The authors developed a dynamic decision support system to help refurbishment contractors. The results of this study confirmed that hosting data in a cloud repository helped the decision taken on site. 
In the construction sector, Grover and Froese (2016) experimented with a socio platform where interdisciplinary stakeholders could collaborate. This investigation demonstrated the importance of contemplating the social layer when collaborating with different stakeholders and not just technical issues.

In the housing maintenance sector, Arthur et al. (2017) designed a central controller that connects a variety of smart devices in the home such as door locks, cameras, lights and thermostats. This platform is hosted in the cloud to enable collaboration and the linking of BIM models with other sources. Arthur et al.'s BIM platform is Big Data enabled, has an Industry Foundation Classes (IFC) compliant BIM engine, and an Internet of Things (IOT) hub for handling loT data. The results show that contemplating collaboration holistically helps improve the quality of the project. Such evidence supports the adoption of a multiple stakeholder's perspective in the development of the research here presented.

Howell et al. (2017) designed a CDE to control urban water solutions with a very articulated platform based on a detailed water value chain ontology. The investigation stated that semantic interoperability solutions are essential, which was the basis on which to build the software architecture of the artefact presented in this paper, namely BIMlegacy. Also, it coincides with Arthur et al.'s (2017) idea, as loT can integrate large data models with dynamic data streams. Thus, this platform supports more powerful applications for operational built environments (Howell et al., 2017).

CDE applications are very useful methods of controlling construction budgets. Jeong et al. (2016) investigated BIM-integrated construction operation simulation for Just-In-time production management, but without creating a formal CDE. Later, Lee et al. (2017) developed a 3D BIM-assisted productivity measurement method prototype for field labour. The advanced construction productivity measurement method allows workers to be more precise in their tasks and perform productivity tracking. The most relevant result is a productivity trend curve, which is based on the application of the prototype to a case project (Lee et al., 2017). The input of Jeong's investigation resides in the data of the case project, which concludes that his CDE improves productivity.

Li et al. (2018) developed an loT-enabled BIM platform for prefabricated construction, tested through a case study. The authors concluded that the platform improved the effectiveness of the team as well as the data collection on site (Li et al., 2018). The success of this study encouraged this investigation to include the construction phase within the HBIM platform.

In conclusion, BIM platforms enabled the synchronisation of the information in many sectors of the construction industry with positive reported results (Li et al., 2018; Lee et al., 2017; Howell et al., 2017; Arthur et al., 2017; Grover and Froese, 2016). Previous studies demonstrate that the communication and information sharing between interdisciplinary work groups improve when using $C D E$, which considers the use of a CDE to improve the workflow in heritage projects. The next section presents a literature synthesis on HBIM platforms to frame existing research in this topic.

\subsection{HBIM Platforms}

The main difference between BIM and HBIM in terms of CDE requirements is that, in heritage projects, an extra layer of historic data needs to be managed (Antonopoulou and Bryan, 2017). Recent 
studies concluded that accessibility to historic information improves the quality of the projects and facilitates decision-making (Antonopoulou and Bryan, 2017). Thus, a common workspace is required to coordinate the different layers of historic and archaeological information. Historical England described the principles that a CDE for heritage problems should have (see Figure 1), which were considered in the development of BIMlegacy. Antonopoulou et al. (2017) stated that a CDE should have the following four folders:

(a) "Work in progress" folder, where the work files are shared, such as HBIM models currently in use where the team is working on archaeological reports that have been written.

(b) "Shared" folder, where the formal submission to the property is delivered. These files would have been verified before uploading the files into this folder.

(c) "Published documentation" folder, where the files are updated once the property has approved the information. This validated data can be used by all stakeholders.

(d) "Archive" contains information such as "as built" old drawings, old models, asset data, or obsolete maintenance information. It can be considered as the project history.

BIMlegacy used this folder categorisation, presented in Figure 1, to structure its internal database.

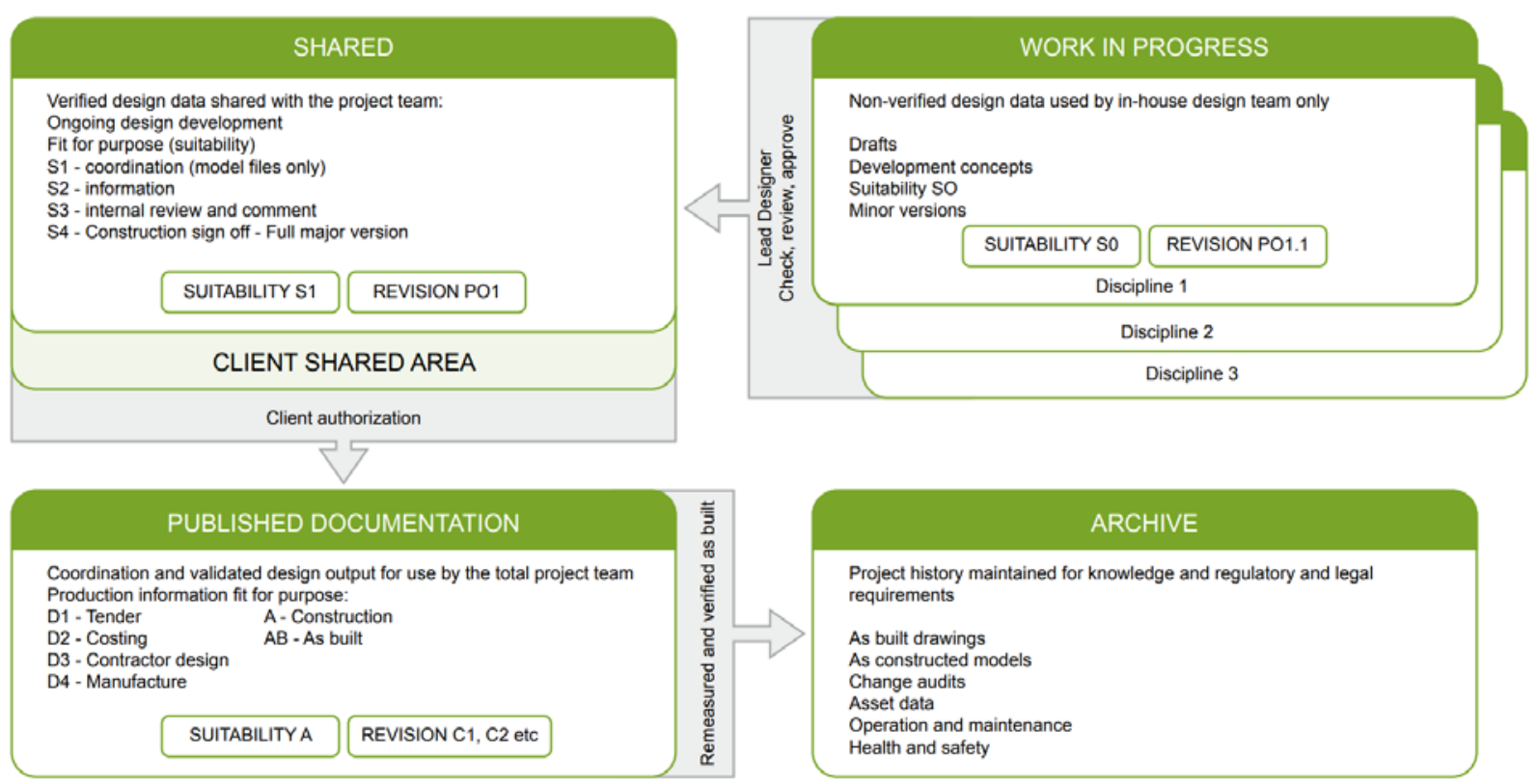

Figure 1. An outline of CDE principles. Historical England (Antonopoulou and Bryan, 2017).

After performing the literature review, it is possible to conclude that there are no CDEs specialised in heritage project management. However, there are internet tools to assist specific activities related to a heritage survey (Spain is Culture, 2018; PetroBIM and Armisien, 2014).

Petro BIM is an example of an internet tool in the heritage sector. It is a basic online tool where HBIM models can be uploaded and be accessible for different stakeholders. It is a data-sharing website and it cannot be considered as a real-time workspace (PetroBIM and Armisien, 2014). Petro BIM focuses 
on the survey stage of the project and does not contemplate the whole life cycle of the building. The benefits of this platform are that the architectonic survey documentation is presented in 3D views and 3D divulgation models, which help stakeholders to understand the spaces and buildings. The limitation is that the model used is not synchronised with the HBIM model, so it does not connect different stakeholders' work.

The Arches project is a collaboration between the Getty Conservation Institute ( $\mathrm{GCl}$ ) and World Monuments Fund (WMF) to create an open-source, web- and geospatially based information system that is purpose built to create an inventory of and manage immovable cultural heritage. The main characteristics of the project are that it is standards based, broadly accessible, economical to adapt and implement, customisable, and secure (Getty Conservation Institute, 2019). The main limitation of the platform is that the information is not synchronised with a BIM model, so it cannot be considered a BIM platform.

Another similar platform is 3DHOP (3D Heritage Online Presenter), which is an open-source software package for the creation of interactive web presentations of high-resolution 3D models, oriented to the Cultural Heritage field (Visual Computing Laboratory - ISTI - CNR initiative, 2019). The main benefit of 3DHOP is its high-quality visualisation. The main issue is that it is not a database but rather a model visualiser. In addition, it is not able to work with BIM because it does not have an intrinsic database where information can be synchronised.

The website "Spain is culture" offers the chance to explore some emblematic monuments in $360^{\circ}$ thanks to an application which combines both educational and informative functions and provides users with an enriching experience. Each monument can be enjoyed in a different context. You can zoom in on of this platform are that it is very intuitive and simple; however, its main limitation is that it is not connected with HBIM models (Spain is Culture, 2018).

The main issues with HBIM, as described in the literature, are that modelling historic structures is a laborious process (Green and Dixon, 2016), HBIM does not yet fully contemplate the historical and cultural legacy of the buildings (Ilter and Ergen, 2015), and it does not take into consideration all heritage stakeholders, e.g. archaeologists, restorers, historians, archivists (Garagnani et al., 2016). These issues could be solved with the creation of an effective HBIM platform; however, according to the literature, there is no specific HBIM platform which unifies in real time heritage information and serves as workspace for the interdisciplinary stakeholders (Dore and Murphy, 2017). This is the knowledge gap that this research tries to fulfil, at least partially.

Table 1 summarises the discussions presented above, highlighting what is missing in the existing BIM platforms to support heritage projects.

\begin{tabular}{|l|l|l|l|l|l|l|}
\hline Platform & $\begin{array}{l}\text { Does it hold } \\
\text { BIM models? }\end{array}$ & $\begin{array}{l}\text { Does it } \\
\text { synchronise } \\
\text { information } \\
\text { with BIM } \\
\text { models? }\end{array}$ & $\begin{array}{l}\text { Informative vs } \\
\text { work platform }\end{array}$ & Customisable & $\begin{array}{l}\text { Have the CDE } \\
\text { requirements } \\
\text { been } \\
\text { fulfilled? }\end{array}$ & $\begin{array}{l}\text { Benefited } \\
\text { sectors }\end{array}$ \\
\hline
\end{tabular}




\begin{tabular}{|l|l|l|l|l|l|l|}
\hline PetroBIM & Yes & No & $\begin{array}{l}\text { Informative but } \\
\text { useful to consult } \\
\text { information in } \\
\text { work teams }\end{array}$ & $\begin{array}{l}\text { There are } \\
\text { different } \\
\text { modules that } \\
\text { can be bought } \\
\text { depending on } \\
\text { needs }\end{array}$ & $\begin{array}{l}\text { Partially, it } \\
\text { requires to } \\
\text { synchronise } \\
\text { information } \\
\text { in real time }\end{array}$ & $\begin{array}{l}\text { Historians, } \\
\text { researchers, } \\
\text { heritage } \\
\text { architects, and } \\
\text { archaeologists }\end{array}$ \\
\hline $\begin{array}{l}\text { Arches } \\
\text { project }\end{array}$ & No & $\begin{array}{l}\text { Yes, after } \\
\text { creating your } \\
\text { own } \\
\text { programming } \\
\text { module }\end{array}$ & Work platform & Yes & $\begin{array}{l}\text { Partially, BIM } \\
\text { model's } \\
\text { visualisation } \\
\text { is missing }\end{array}$ & $\begin{array}{l}\text { Historians, } \\
\text { researchers, } \\
\text { heritage } \\
\text { architects, and } \\
\text { archaeologists }\end{array}$ \\
\hline 3DHOP & $\begin{array}{l}\text { Yes, after } \\
\text { change } \\
\text { format }\end{array}$ & No & Informative & No & $\begin{array}{l}\text { Partially, it } \\
\text { requires to } \\
\text { synchronise } \\
\text { information } \\
\text { in real time }\end{array}$ & $\begin{array}{l}\text { Culture tourism } \\
\text { and monument } \\
\text { managers }\end{array}$ \\
\hline $\begin{array}{l}\text { Spain is } \\
\text { culture }\end{array}$ & No & No & Nongang & No \\
\hline
\end{tabular}

Table 1. Summary of existing BIM platforms

It is clear from the data presented in Table 1 that CDE requirements have not yet been properly considered on existing platforms. This is the case, as there are platforms that address only non-technical stakeholders and other platforms that consider just technical stakeholders' needs. What is needed to bridge the gap between what is available and what should be available is to synchronise information in real time and to generate a platform that enables the involvement and collaboration of all heritage project stakeholders.

\section{Research method}

DSR was the research approach adopted, as it focuses on solving practical problems with theoretical relevance, providing theoretical and practical contributions (Holmström et al., 2009). As this research focuses on solving a practical problem, namely creating a CDE for HBIM projects, DRS was considered the most appropriate approach to undertake the research.

Figure 2 represents the research design adopted, which was divided into five stages (Peffers et al., 2007): identify the problem, define objectives, design the solution, implement the solution, and evaluate the solution. The problem is identified through the literature review and an analysis of heritage architecture processes and requirements allowing the definition of objectives. Subsequently, the design of the artefact takes place. The artefact is implemented in the San Juan case study. Finally, the artefact and its implementation were evaluated through a focus group with external stakeholders. 

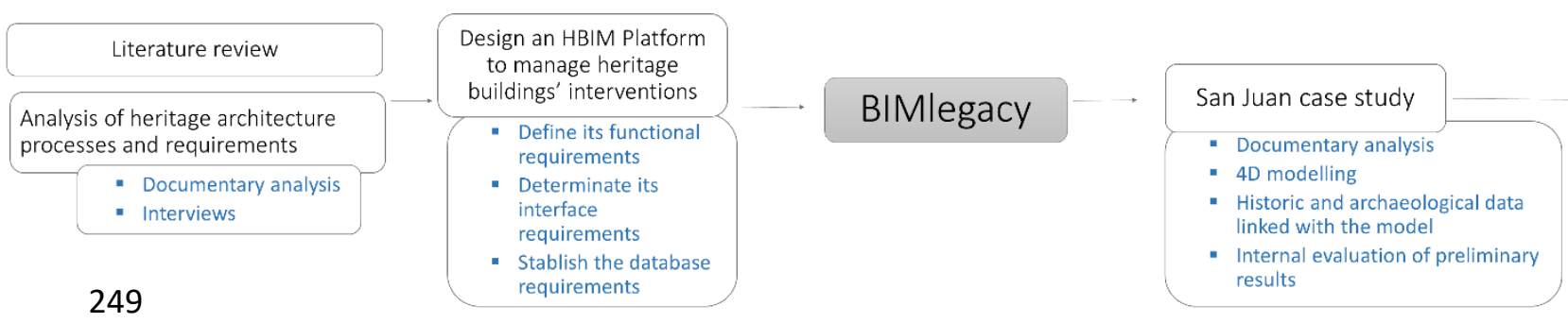

Focus group with heritage and BIM external stakeholders, Spain External evaluation

Figure 2. Research method.

The problem in HBIM adoption by the heritage sector was initially identified through a review of the literature. As the research gap was defined, an analysis of the heritage architecture processes and the future HBIM platform requirements was developed. In order to understand the platform needs (Fai et al., 2011), data was collected through document analysis (e.g. design drawings, technological implementation plans, databases) as well as ten semi-structured interviews with relevant heritage professionals representing two relevant monuments, i.e. the Sagrada Familia Temple and Santa María of Vitoria Cathedral (Faulí). The interviewed stakeholders were: architect (13 years' experience), BIM manager (5 years), construction manager (8 years), restorer (14 years), technical architect (18 years), archivist (25 years), topographical surveyor (22 years), archaeologist (21 years), monument manager (27 years) and heritage diffusion expert (12 years). The questions asked included: What departments are involved in managing your monument? Which stakeholders are involved? How do you archive the produced information? The results obtained included a list of stakeholders likely to be involved, an organisational chart of both monuments, and a list of initial requirements to develop the HBIM platform.

Data analysis supported the definition and refinement of the objectives to design BIMlegacy, a HBIM platform where heritage stakeholders work in real time and share information. The objectives were to investigate the functional requirements, the interface requirements and the database requirements to design the BIMlegacy prototype.

The next stage was the design of the artefact itself, the BIMlegacy prototype, to which two teams contributed: the heritage team and the supporting IT team. The heritage team worked on the list of heritage stakeholders' needs, functional requirements, and analysed how to make the platform useful for future users, as well as the user interface design. This team comprised of two heritage architects, one BIM

272 manager, one BIM modeller, one engineer, one technical architect, one archaeologist, one historian, and 273 one monument manager. The team members-practitioners have extended experience with heritage projects and/or BIM professional practice. Thus, their own experience was also called on to build the platform. The supporting IT team was involved in the database requirements, software solution, and plugin connexion. This team was composed of two computer engineers ( 2 years' experience) and one management information engineer (10 years' experience). The design process of BIMlegacy involved the following tasks: 
records were transcribed, and information analysed using Nvivo (a tool to analyse qualitative research data). The data was coded and the results displayed in conceptual diagrams.

2. Analysing current heritage databases to understand the basis of heritage documentation (Howell et al., 2017). This step entailed the analysis of the existing HBIM platforms, which was presented in the Literature synthesis section of this paper.

3. Defining the workflow in BIMlegacy. Flowcharts were developed to order and connect the functioning of the platform. Figure 3 is one of the flowcharts developed to organise the processes of BIMlegacy platform. Figure 3 represents the following chronological tasks:

0 The monument manager sends email invitations to the heritage stakeholders involved in the project in order to join the platform.

290

291

292

293

o The first step is to create a work group with the heritage stakeholders who have accepted the invitation. The group will work in BIMlegacy as a CDE to synchronise its work.

o Different permissions are given depending on the stakeholder's role and credentials. These permissions are controlled through an ID and user.

o After the previous studies, the monument is divided into sectors to facilitate the organisation of the information.

0 The monument surveying is performed. This is to document the condition of the building with the architectonic survey, materials, and pathologies.

o Three main tasks need to be performed: (1) the architectonic BIM model that is generated by architects and technical architects; (2) the archaeological BIM model, performed by archaeologists; and (3) the historical data collection, which is done by historians and art historians.

0 The synchronisation of these three kinds of information in real time, represented in Figure 3 with round double arrows, is the key to the functioning of the BIMlegacy platform. 


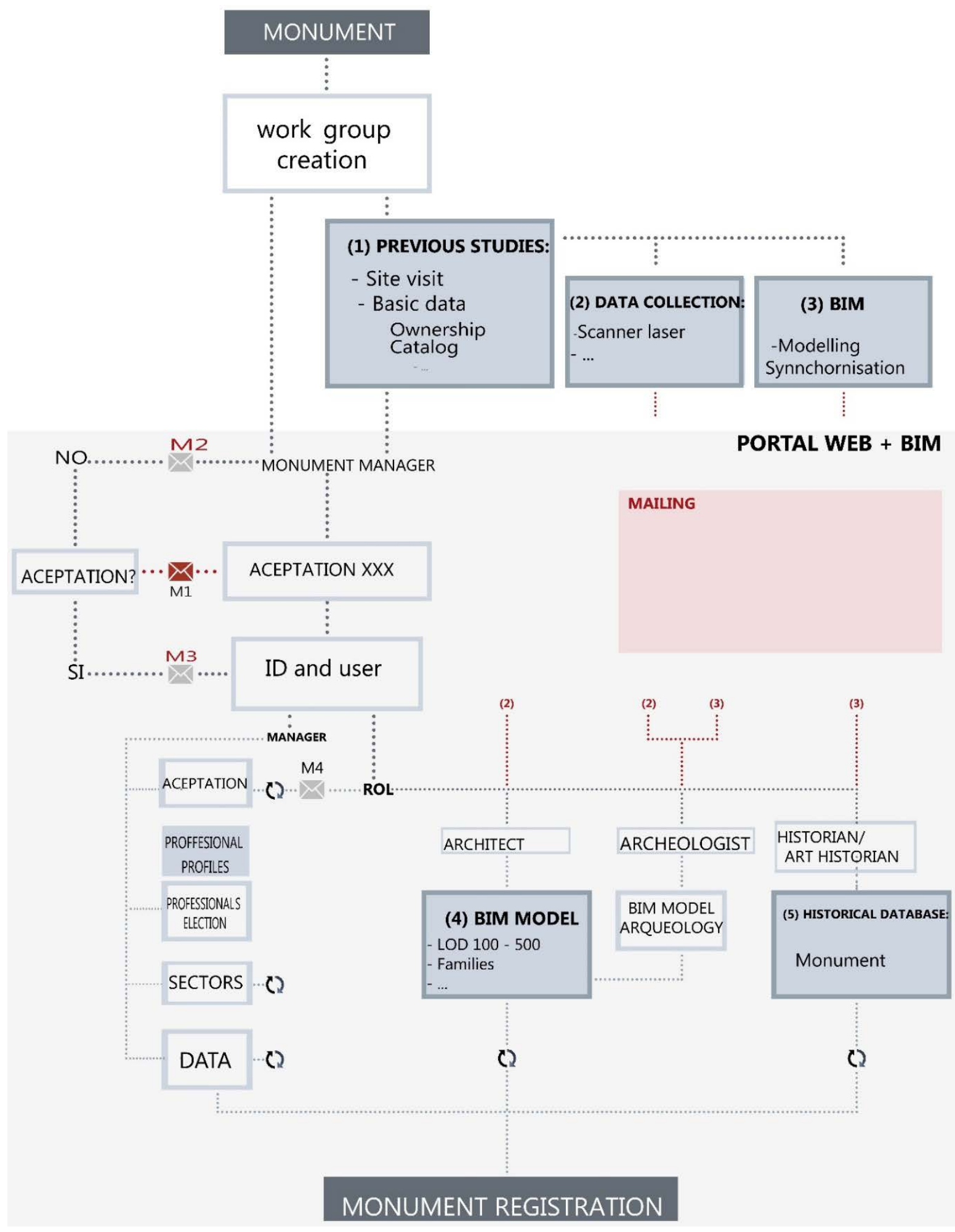

Figure 3. Workflow in BIMlegacy

307 4. Settling the database categories. The four elements presented in Figure 1 (CDE according to Historical 308 England) were used as a skeleton to define these categories. 
5. Designing the interface and corporative image of the BIMlegacy platform. This was designed considering heritage values using colours and forms that resemble ancient buildings.

6. Definition of the different roles of the workspace and their permissions. The list of stakeholders was defined from the analysis of the semi-structured interviews with the heritage stakeholder and the literature.

7. Designing HBIM templates for private heritage buildings to upload in the BIMlegacy website to help future users to develop their projects: BIMlegacy BIM Execution Plan (BEP), BIMlegacy Revit software of Autodesk templates, and HBIM families (Gerçek et al., 2017). BIMlegacy can also hold IFC open BIM files or models coming from other software such as Allplan (Nemetschek), Archicad (Graphishoft) or Bentley AECOsim (Bentley Systems). However, if these are used, the information cannot be synchronised in real time.

8. Establishing the HBIM modelling requirements to use the platform. BIM modelling requirements were defined after analysing the HBIM literature, HBIM guides (Building SMART Spanish Chapter, 2014; Maxwell, 2014; Council, 2013), published HBIM case studies (Grover and Froese, 2016; Ilter and Ergen, 2015; Eppich and Chabbi, 2007), and HBIM projects where the team members were previously involved in their own professional practice.

9. Programming the platform. The goal was to map the identification database of the Revit intrinsic database with the BIMlegacy online platform (Quattrini et al., 2015). The requirements of the IT solution were settled, and the programming work started. The IT team and the heritage team collaborated when programming the platform. A total of ten versions of the prototype were developed, each of them improving the previous one. A series of tests and checks were achieved with the plug-in, server, and website.

10. Hosting the platform in a Wide Area Network (WAN) to make it accessible from different geographic locations. This was one of the functional requirements defined at the beginning of the investigation (Perng et al., 2007).

11. Performing error proofing with different devices to assure the designed platform can work on different computers, tablets and smartphones.

BIMlegacy was implemented in the registration project of San Juan del Hospital of Valencia heritage asset (Garcia and Lopez, 2014), which was declared a Historic Artistic Monument at National Lin in 1943. The San Juan heritage asset is composed of a church, an old cemetery, and a courtyard. During the twentieth and twentieth-first century, the building underwent various restorations, but further interventions are needed, as well as preservative maintenance. San Juan stakeholders were about to start a new intervention phase and, after hearing an explanation of what the BIMlegacy prototype was, they decided to get involved in the research.

San Juan del Hospital of Valencia was chosen as the pilot case study as it includes a set of important characteristics: it is a medieval historical building with complexity regarding constructive phases, and it has available a wealth of information about the site and its development over time. Also, it has had previous intervention projects, it has a variety of stakeholders, and it was accessible for the research team. San Juan has been the subject of recent restoration projects where BIM was not used. This made it possible to compare the results of this project (carried out with BIMlegacy) with the previous project results. 
The project lasted 18 months, and a total of ten people were involved:

- Heritage architect, manager of the project, 22 years of experience.

- Architect, experience as historian, 15 years of experience.

- BIM manager, 4 years of experience.

- BIM modeller, 2 years of experience.

- Systems engineer, 14 years of experience.

- Technical architect, construction manager, 12 years of experience.

- Archaeologist, 18 years of experience.

- Director of San Juan, monument manager, industrial engineer, doctor in theology, rector of the church, 3 years of experiences.

- Computer graphics manager, cultural diffusion, Degree in Advertising and Public Relations, 3 years of experience in San Juan and further experience in similar works.

- Director of the museum, archivist, artistic manager, Professor of Drawing, degree in Fine Arts, 25 years of experience.

- Contractor, technical architect, 20 years of experience.

Some of these stakeholders are the same as those that participated in the creation of the BIMlegacy platform. The application of BIMlegacy in San Juan entailed the registration of the monument in the platform, the invitation of all the stakeholders, filling in the fields of the platform database, building modelling, and the continuous synchronisation of both the 3D model with the work website. The modelling consists of a laser scanning survey, a 3D modelling of this heritage asset using Revit (Autodesk Company software), previous historical phases modelling, archaeology remains modelling, and the representation of materials and pathologies. Historic, archaeological, and cultural documentation was performed by the archivist and the art historian using the BIMlegacy online workspace. The HBIM model was synchronised and updated with the BIMlegacy online workspace, enabling all stakeholders to work together in real time. It also included the generation of the construction budget by the technical architect in collaboration with other stakeholders.

The BIMlegacy platform and its application in the San Juan project were presented in two simultaneous focus groups to evaluate its effectiveness and efficiency. The focus groups were used as a data collection method. Data was collected through two semi-structured interview processes and it was moderated by two facilitators. The aim of both focus groups was to collect data on HBIM processes and requirements. The focus groups were to consider the following characteristics:

- Standardisation of questions: There were seven questions in each focus group, and they followed a structured protocol. The focus groups were carefully prepared, sending invitations to the potential participants and preparing a common short presentation to introduce the research.

- Number of focus groups conducted: There were two focus groups because of the different stratifications of the participants (e.g. methodological/academic background and technical/professional background).

- Number of participants per group: There were six participants in the methodological focus group and five in the technical one, so 11 participants in total.

- Level of involvement of the facilitator: The degree of control exercised within the focus groups was high because structured questions were asked, and the group dynamics were actively managed. The facilitators were members of the research team who were prepared to provide 
clear explanations of the purpose of the group, help people feel at ease, and facilitate interaction between group members (Gibbs, 1997).

The focus group was located at the Universitat Politècnica de València and comprised interdisciplinary participants. The participants of the focus group included a BIM consultant (6 years of experience); a BIM university professor with knowledge in heritage architecture (18 years); a BIM specialist who is also a construction engineer (4 years); a BIM architect with experience in heritage (25 years); and a planning consultant who uses BIM (10 years). The questions asked were: "Which difficulties do you find in modelling historical buildings after seeing the results of this case study?", "Do you think that the case study was documented in an appropriate way?", "Do you think BIMlegacy is effective?" They concluded that the BIMlegacy platform is useful to manage heritage projects and proposed further improvements to the prototype platform. Even though this focus group provided useful insights regarding the BIMlegacy's practical applicability, it is a partial validation only as it had limitations, e.g. the participants did not practise for long enough with the platform to fully understand its possibilities and challenges.

\section{Proposal of the BIMlegacy platform}

BIMlegacy entails a CDE for the heritage architecture sector unifying heritage architecture information. The platform is composed of a work website, a heritage diffusion website, a Revit plug-in, and a WAN server. Revit was chosen as the BIM modelling software because of its open programming core, its database structure, and its good interoperability.

Cultural diffusion is crucial for the preservation of heritage buildings. As a consequence, BIMlegacy has a free access website which can be used to disseminate information about the registered monuments for cultural purposes. It was designed to be both a work platform and a diffusion tool to bring the cultural legacy to the society.

The BIMlegacy prototype has been developed in Spanish and it is currently located on a LAN server granted by the Universitat Politècnica of València. The design of BIMlegacy is responsive, which allows it to be used on mobile devices such as tablets or cell phones, thus aiding user mobility.

\subsection{Platform architecture}

The elements connecting the different databases of the system, represented in Figure 4, are as follows:

- A plug-in that consist of a Software Developing Kit (SDK) Application Programming Interface (API) for Revit. This plug-in retrieves the needed information from the Revit model and consumes WebApi to synchronise the data of the Structured Query Language (SQL) server's data with the Revit file data.

- A WebApi. This is an applications programming interface published on the server web. The plugin connects this WebApi to interchange information. The WebApi is independent from the plugin and other types of applications; for example, it could be used on a mobile application.

- The Revit Core is a Dynamic Link Library (DLL) responsible for managing the business layer and the data access. 
- A database SQLServer is based on a relational model allowing working in a client-server mode. It stores information in the cloud, supports millions of registrations and its users have no limitations.

- A web portal, which facilitates data insertion, editing and consultation in any graphical location. It would be oriented to non-technical stakeholders who do not usually work with BIM (e.g. historian, art historian, monument manager) and to external visitors.

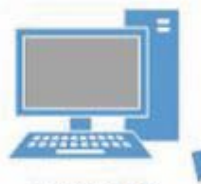

PC con REVIT
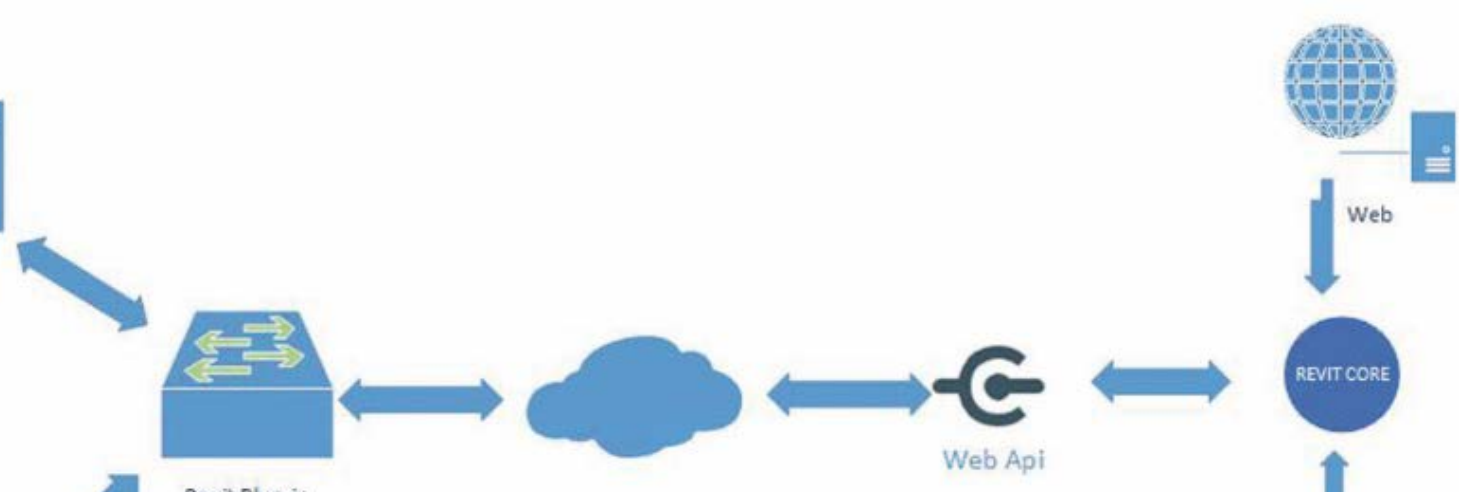

Revit Plug-in

Internet

Web

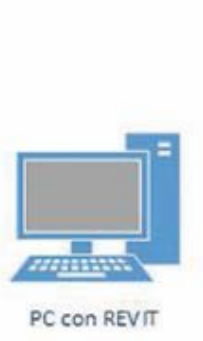

and

Fig 4. Computer architecture, 2016

Basically, technical stakeholders work in 3D Revit models and the Revit parameters are mapped with the database fields of the documental web through a semantic recognition system. The plug-in filters the BIMlegacy parameters from the rest of the parameters of the Revit models and controls the possible changes made within these parameters. The non-technical stakeholders work on the website, filling the documentation fields, and adding photographs, drawings, and reports.

Synchronisation is the main characteristic of BIM. For this, the prior definition of a common space, a WAN server, was required to harmonise the data. A WAN server is automatically created when downloading the plug-in from the website. This WAN server allows the hosting of central HBIM models, where all the technical stakeholders can work together in real time.

\subsection{BIMlegacy interface}

The interviewees highlighted that the platform should be user friendly and simple to use. BIMlegacy was designed with a simple and intuitive interface to facilitate its use. The graphic design conveys heritage values. It has eight screens with a lateral navigation bar that contains the following sections: management, general data, sectors, BIM, manuals/templates, images, graphic information. This is explained in Figure 5, and includes the following elements: 
- Management is where the monument manager can invite other participants, control the roles, and add the essential information.

- General data allows the addition of the monument information, fiscal data, written and graphical description, preservation condition, constructive evolution, and bibliography.

- Sectors tab directs the stakeholders to the different parts of the monument. For example, if the monument is a church, one sector can be one chapel, another sector can be a vault.

- In the BIM tab, complementary HBIM files are placed (i.e. BIM families, HBIM templates, and point clouds).

- Gallery contains pictures and drawings of the monument, for example old pictures that need to be archived as cultural documentation.

- Plans tab contains all the sections, facades, and plans of the current project or previous projects carried out in the building.

- Reports is the section designed to upload any kind of reports of the building related to the current project or with previous ones.

- Users is the section where users can be managed, and roles can be reassigned. This tab should be managed by the project manager.

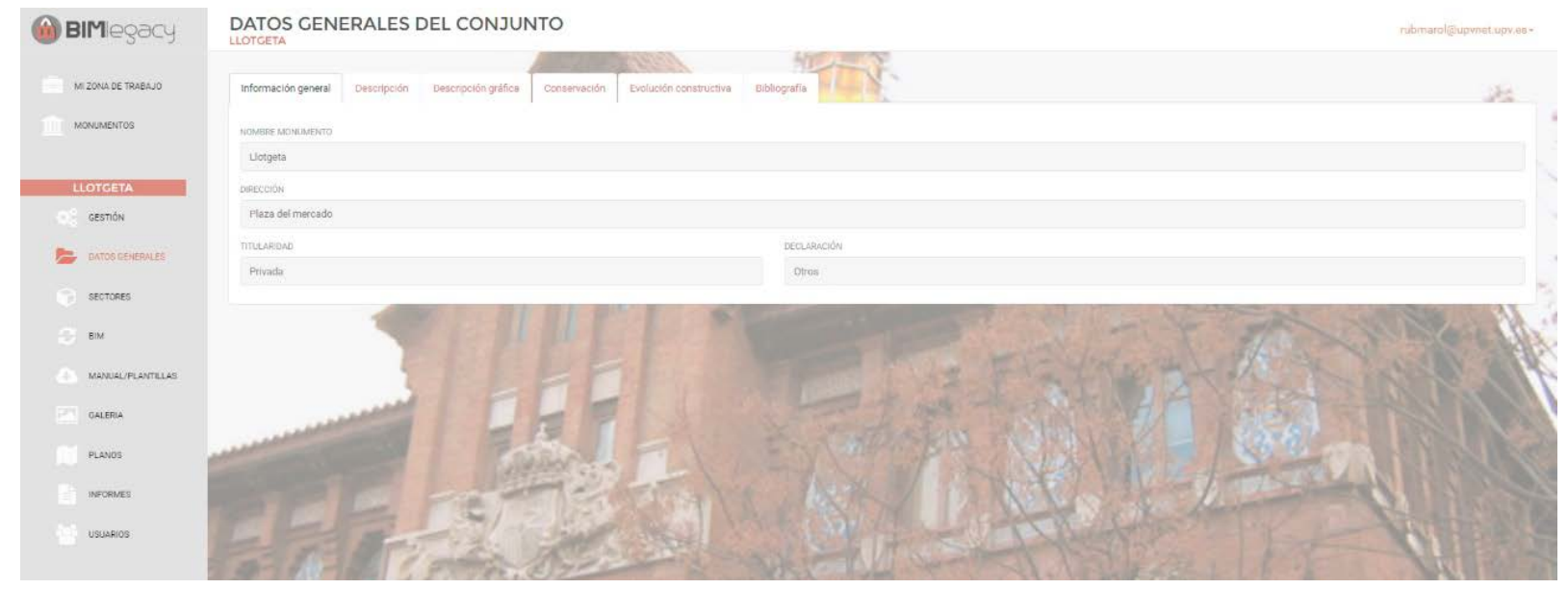

Fig 5. BIMlegacy worksite interface, 2016

The BIMlegacy interface addresses the issues raised in the literature related to the need to include simple tools for non-technical stakeholders. The BIMlegacy interface is easy to use and designed for nontechnical stakeholders (Garagnani et al., 2016). One thing that could not be addressed with the BIMlegacy interface was the need to include a BIM visualiser in the website (Dore and Murphy, 2017), which could be considered in future research.

\subsection{BIMlegacy Workflow}

The goal is that users focus on their own work and not on the website functioning. Basically, three groups of people can use the platform: (1) technical stakeholders, who use the website as a secondary workspace where they can download useful files (i.e. the plug-in, the BIMlegacy template, and the HBIM families) and consult information; (2) non-technical stakeholders, who use BIMlegacy as HBIM workspace to fill in documentary fields and load reports; and (3) generic public or visitors, who use it as a consulting 
website to search for historic-artistic information. Visitors do not need to be registered to benefit from the information archived in BIMlegacy. Nevertheless, not all the information in BIMlegacy is accessible to visitors, as it is filtered to preserve the privacy of monuments. The BIMlegacy workflow addressed one of the main concerns in HBIM literature, namely to include non-technical stakeholders within the HBIM workflow (Quattrini et al., 2015).

487

488

\subsection{Database fields of the platform}

Three levels of documentation were created to order and divide the information on the database, from general to specific: monument, sectors, and items. Those levels are directly related with these items in Revit: project file, families, and sub-families. Monument information is the generic data of all the monuments (e.g. monument style, location). Families are constructive units (e.g. arc, volt) and their information fields are related to specific information regarding the constructive element (e.g. constructive system, material). Items are single elements that need to be registered and documented due to their singularity or values (e.g. a carved stone) and the information associated (e.g. author, technique). Items are sub-families of Revit. Thus, the information regarding these three levels of the database can be synchronised with just one of the three types of Revit items previously named.

The platform searches for the ID of the HBIM elements to synchronise with the work website. Each family or item will belong to a BIM category (e.g. floor, celling, column). Figure 6 shows the different categories and the parameters associated with each of them. Not all categories require all parameters, thus there are categories, such as model_element, that have a greater number of parameters.
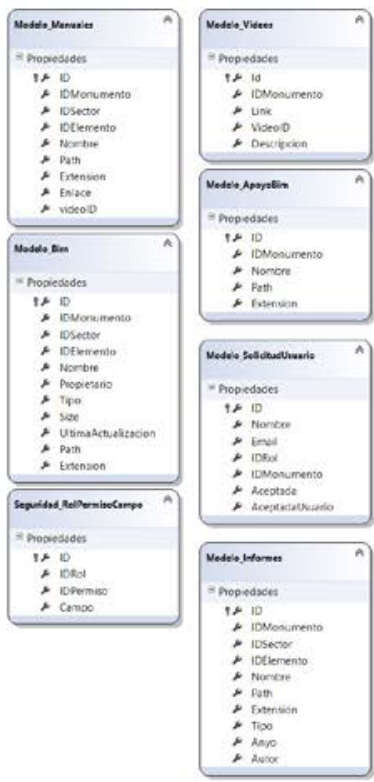

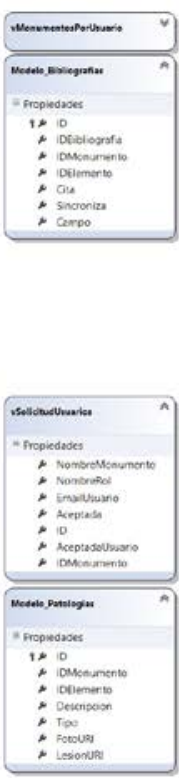

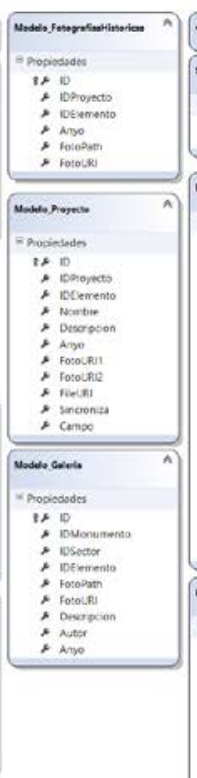

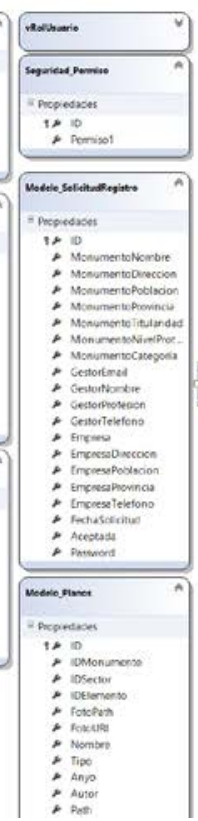

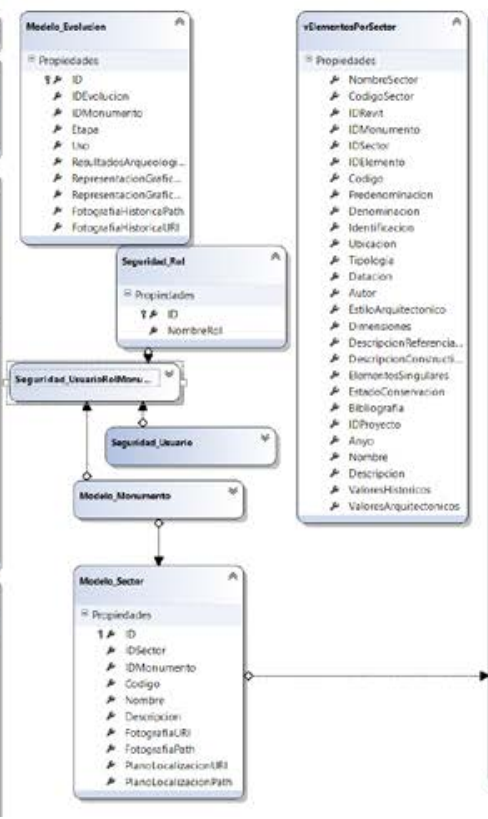

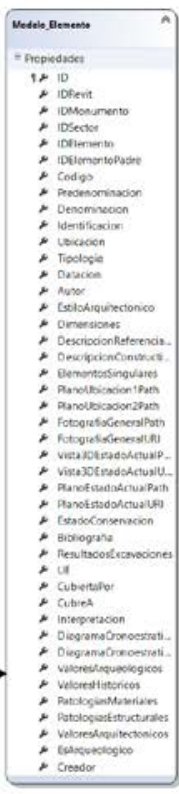




\begin{tabular}{|c|}
\hline Model_manual \\
Properties \\
ID \\
ID Monument \\
ID Sector \\
ID Element \\
Name \\
Path \\
Extension \\
Link \\
Video ID \\
\hline
\end{tabular}

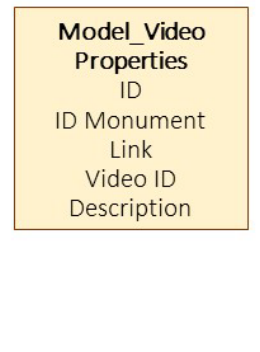

Fig 6. Computer architecture, 2016

The Revit project parameters are synchronised with the monument website fields. The Revit family parameters are synchronised with the sector website fields. The sub-family parameters in Revit are synchronised with the singular elements fields.

These fields are assimilated as Revit parameters in the BIMlegacy template, previously created as part of this research project. All the Revit parameters that are liable to be synchronised with the work website have the HBIM characters starting with the letters BIMle, as shown in Figure 7. This is a screenshot of a Revit family properties menu, where the information of the website is already synchronised with the website data.

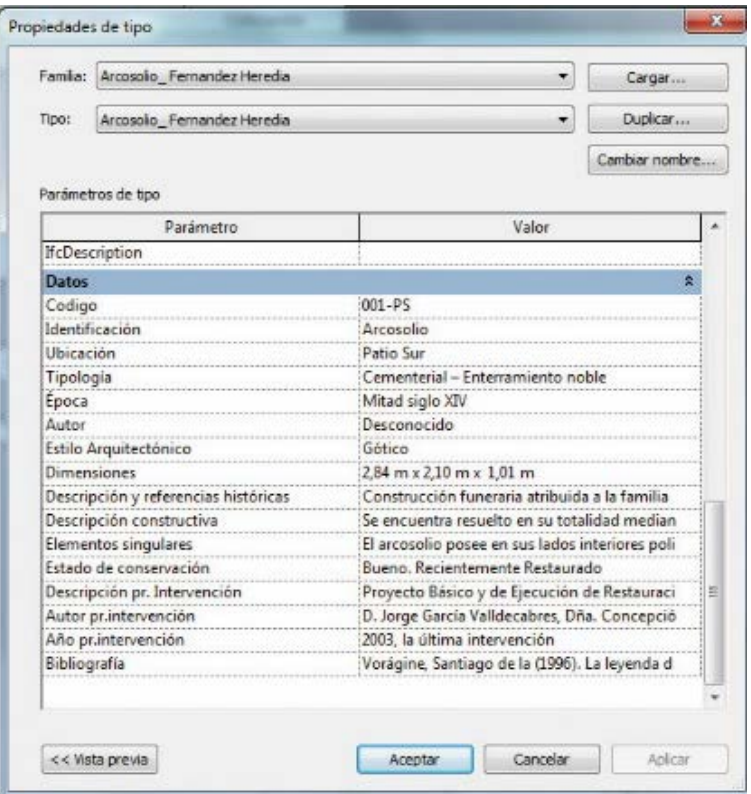

Fig 7. BIMlegacy parameters with the prefix BIMle in Revit, 2016

Regarding permissions, fields have edition permissions depending on each professional's profile. Each stakeholder can visualise all fields and edit exclusively those fields with editing permission. Each professional profile can only fill in their discipline fields. Technical stakeholders, who are more likely to work with BIM, can insert, edit, and visualise the fields via the Revit software. Non-technical stakeholders, who do not work with BIM software, can insert, edit, and visualise different fields via the portal web. The BIMlegacy database addresses the issue raised in the literature in respect of the synchronisation of the 
information in real time of different databases with the possibility of controlling the permits (CamarinhaMatos et al., 2017), which is the authors' contribution.

\subsection{BIMlegacy User tests}

This platform prototype has been tested on 20 computers and devices, from high-end HP tower computers with 32GB of RAM memory and Nvidia GTX 1080 Ti graphic card, to simple laptops with 8GB of RAM memory and basic graphics. All computers had Windows operative systems and a commercial antivirus. Different issues emerged when doing the testing, but the most problematic points of the BIMlegacy functioning were the automatic emailing, the permissions of the fields, and the correct installation of the plug-in in different operative systems. The automatic emailing and the correct installation of the plug-in were solved by identifying the problems and hypothesising the solutions. The platform was tested on as many devices as possible and the code solution that better resolved the problem was incorporated in the next version of the platform code. The permission of the fields was solved by adding just one editing permission to each field, so that other users can either only see or inform.

\section{6. $\quad$ Modelling files of BIMlegacy}

BIMlegacy requires specific heritage HBIM files to support its use in real projects. The BIM Execution Plan (BEP) is the document that descirbes the operational planning when using BIM. The heritage team designed a BIMlegacy HBEP template which can be provided for future platform users since there was no HBEP template available on the market. The HBEP template was generated after extensive analysis of the uses in HBIM and taking, as reference, important BEP templates (Gerçek et al., 2017).

Also, a heritage Revit template was required. Templates are empty files used to start the projects according to quality standards in response to the project organisation, the development planning, the optimisation of workflow, the nomenclature control, and the definition of appropriate views (e.g. international standards, such as ISO or DIN). In order to design the heritage template, the standardisation of the characteristic elements of the monuments were sought.

\section{BIMlegacy implementation in a case study}

BIMlegacy was used to manage the intervention project in San Juan. Different organisations and professionals were involved in this project such as La Fundación de San Juan del Hospital and the Instituto Universitario de Restauración del Patrimonio of the Universitat Politècnica de València (the IRP), a public Spanish institution dedicated to promoting heritage conservation research and practice, and the investigators of this research.

San Juan was modelled with HBIM and documented with BIMlegacy. All stakeholders participated actively in the BIMlegacy platform, and the technical stakeholders also modelled San Juan with HBIM, specifically with Revit. All the stakeholders synchronised the information in real time. Different stakeholders were more actively involved, depending on the phase of the project. In the first stages, the archivist and the monument manager had a greater workload, while, in the last phases of modelling, the architects, the BIM manager and BIM modeller had greater workloads. 
The process started with the registration of the monument in BIMlegacy and the invitation of the involved stakeholders to the project, each one with their own role. San Juan stakeholders were in different 558 geographical locations, which was perfect in order to prove the effectivity of BIMlegacy, which is designed to facilitate work in different locations. The tasks distribution among stakeholders was managed through

560 BIMlegacy (e.g. the general exploration of the building, the definition of the strategy of the intervention 561 project, etc.).

562 The historian and art historian performed the data recollection (Ordeig y Fernández, 2007; Ordeig, 2000; 563 Lassala, et. al, 1999). This implied a search in the archives, private collections, historic cartography of the 564 city, and special bibliography. The graphical documents can be divided into photographs, etchings, and 565 blueprints. The latter belong mostly to the different architectonic surveying and intervention projects. All 566 this data was summarised and inserted by the archivist and the historian in the BIMlegacy monument. 567 After synthesising all the data from their investigations, they inserted the information in their specific 568 fields on the work website. The website synchronises this information automatically with the HBIM model, 569 so the technical stakeholders can see all the information that the non-stakeholders are adding in real time. 570 The fields are modifiable and visible, depending on the assigned role. The WAN server was automatically 571 created when downloading the plug-in from the website. All stakeholders worked simultaneously, 572 visualising the changes that other team members had done.

573 The BIM manager prepared the technical team BIMlegacy HBEP, which was filled with the specifics of the 574 San Juan project. The HBIM BEP of the San Juan project was updated in BIMlegacy so that all stakeholders 575 could consult the latest version. The analysis and recognition of the constructive elements and materials 576 were documented. The information related to the building condition was archived in BIMlegacy focusing 577 on the structural elements, the materials degradation, and the mechanical and electrical condition. The 578 building condition was good due to the preservation maintenance that was carefully performed on the 579 monument. The values and the relevance of the historic asset were studied, synthesising a large amount 580 of documentation and uploading this into the BIMlegacy work website.

The HBIM 3D architectonic survey began with the laser data collection. A scanner laser was chosen 582 to perform the data collection because it was proven to be a better system to document historic buildings 583 conditions with accurate measurements (Afsari et al., 2016). This included the church, the north and south 584 courtyards, and even the asset roofs. The scanning was carried out using a Leica Scan Station C5 with a 585 complete visual field of 360 × $\times 270$ o, very high resolution, with a range of $35 \mathrm{~m}$ and scanning speed of 58625000 points per second. Each scanning positioning creates its own point cloud, and all the point clouds 587 were united and cleaned using Cyclone software and Scene software. 


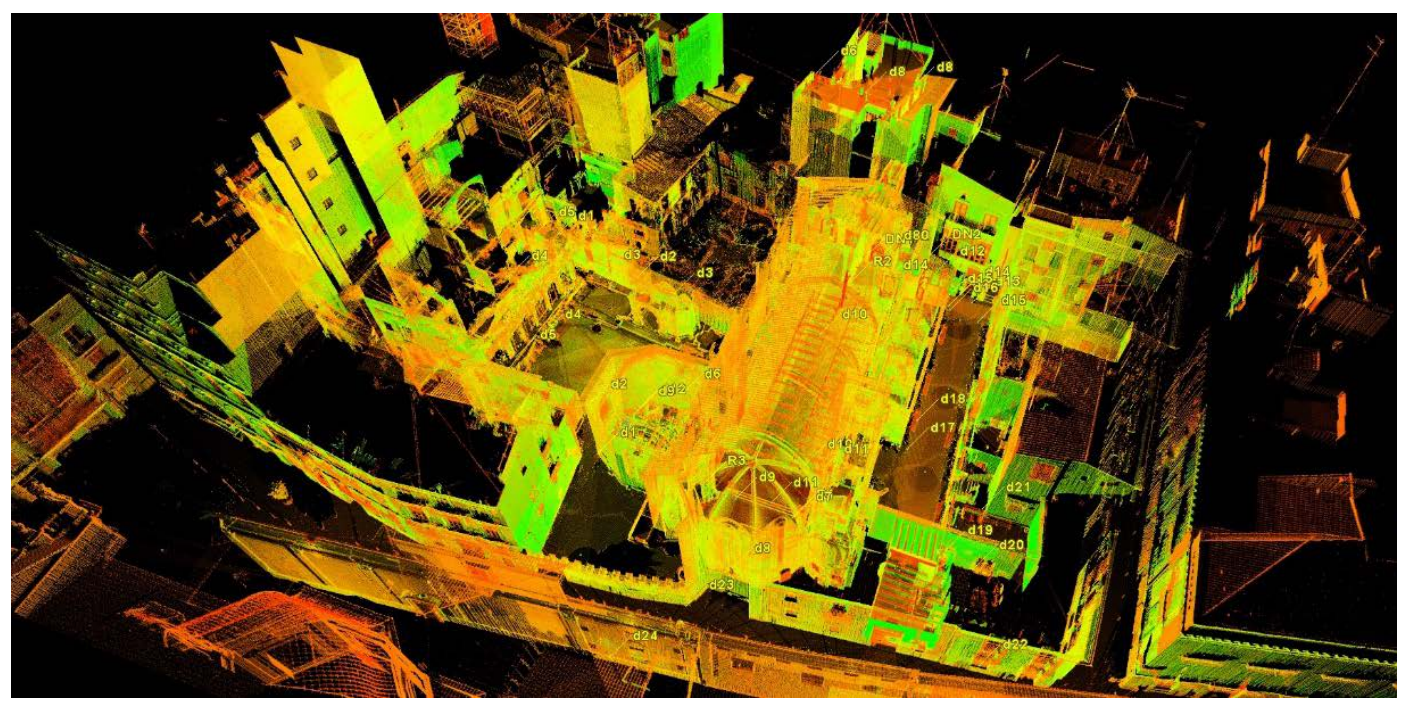

Fig 8. Data collection with the laser scanner in San Juan.

A new project was opened using the BIMlegacy historical architecture template, which had been previously designed. The users' profiles were generated on the BIMlegacy website to give access to the central model, i.e. the master file, where all the changes made by other users can be seen. San Juan was modelled, taking the point cloud as a starting point. The point cloud of all asset assumes an accurate and exhaustive data of the current condition of the asset, so it was used to model the existing state of the asset (see Figure 8). These tasks were carried out using Scan to BIM methodology, the emerging technology to transform point clouds in geometrical items. The HBIM modelling was performed using Revit, achieving a level of development (LOD) of 400. The HBIM model included sub-projects separated by categories: urbanism, architecture, archaeology, structure and M\&E. Initially, a general modelling was performed, building the general shapes of the building and the general locations of the site.

The specific modelling was carried out detailing the virtual model through freestyle shape elements. This is very important in heritage projects, as it is necessary to represent pathologies, crashes, masonry bonding, and deterioration level. The alterations due to the passage of time, such as flaws and material imperfections, cracks, etc., were also represented as they were documented on the BIMlegacy website.

The model was complemented with materials and families, which are files with sets of twodimensional or three-dimensional elements already designed that can be used in the projects and that provide detail to the model. There are not many historic families on the market, hence the design of our own families of heritage elements was needed. 


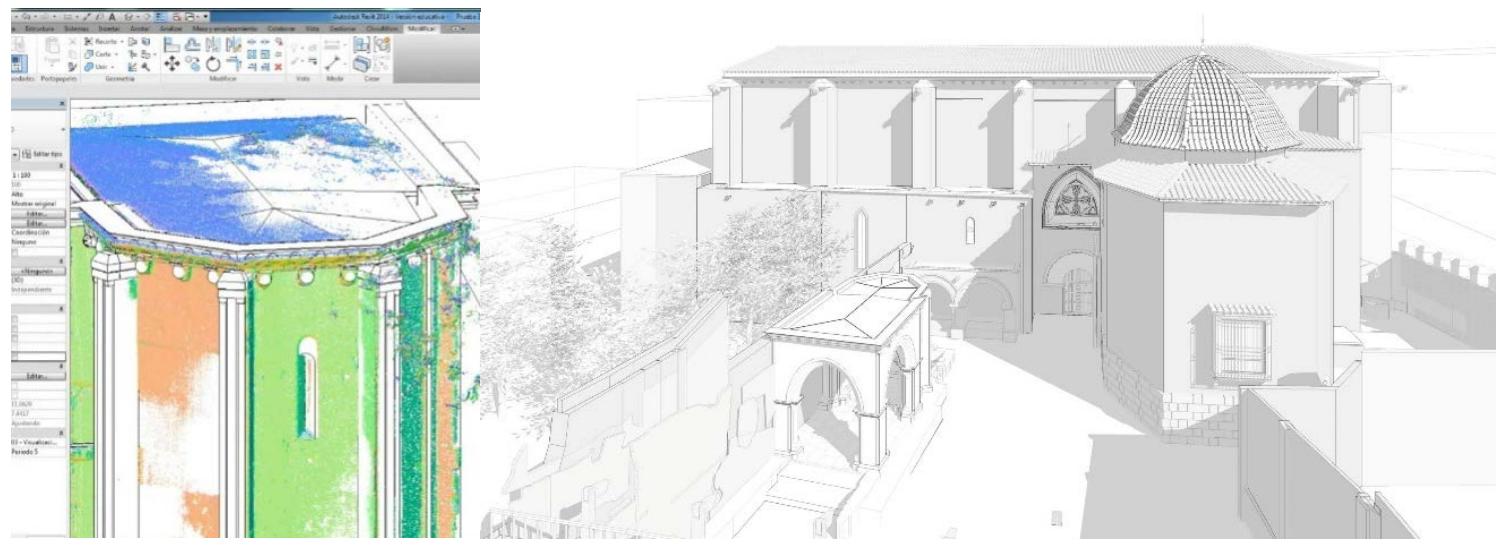

Figure 9. Modelling process based on the point cloud previously created.

The alterations that had taken place due to the passage of time (e.g. flaws and material imperfections, crashes or seats, cracks) were also represented by applying historical periods. It is recommended to initially model items as they were designed in their original state, thus the elements created can be archived in BIMlegacy, and the work is more systematic and standardised as a result (Figure 9).

Archaeology is fundamental to our understanding of and situating the historic-constructive elements, as well as for the generating of monument documentation (see Figure 10). The information to situate the archaeological remains comes from archaeological reports generated in previous archaeological campaigns. After the documentation in BIMlegacy, the archaeological remains were modelled in a separate HBIM subproject and in three archaeological levels so as to order the archaeological remains according to historical periods: Roman, Arab, and medieval.

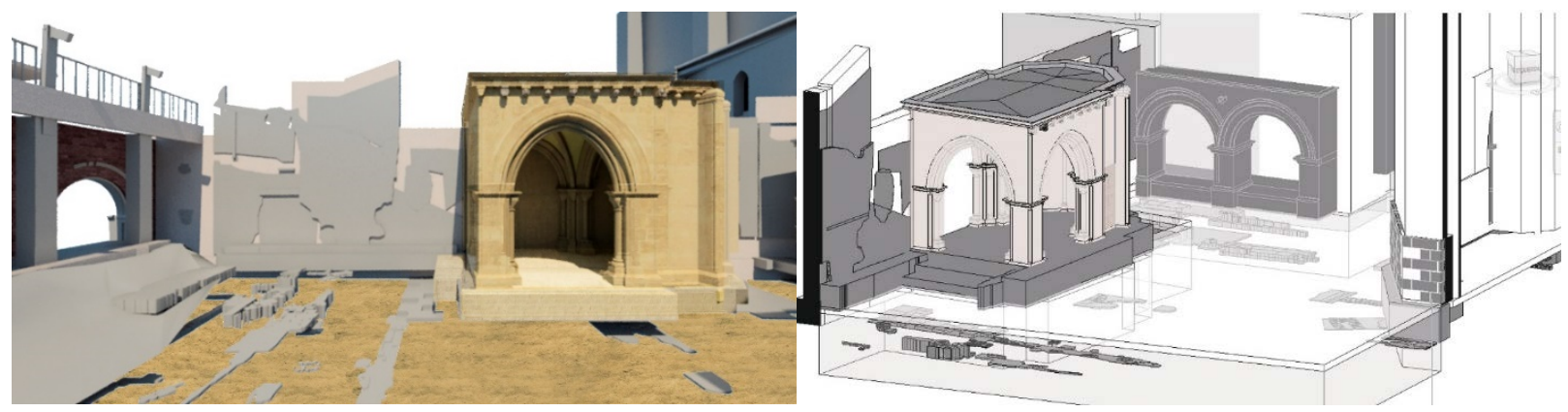

Figure 10. Archaeologic remains modelled in San Juan's HBIM model.

Historic buildings undergo several shape and structural changes during their life cycles (Figure 11). The constructive evolution of the building is now known due to the documentation in the BIMlegacy workspace. Those historical phases must be documented within the HBIM model, but with less LOD since there was not enough information about how the asset was in the past. Pictures were used to provide additional information. Pictures of the current state of the structure can be added to the model. They were added in BIMlegacy, which is synchronised in real time with the model so that the information can be consulted (see Figure 11). 


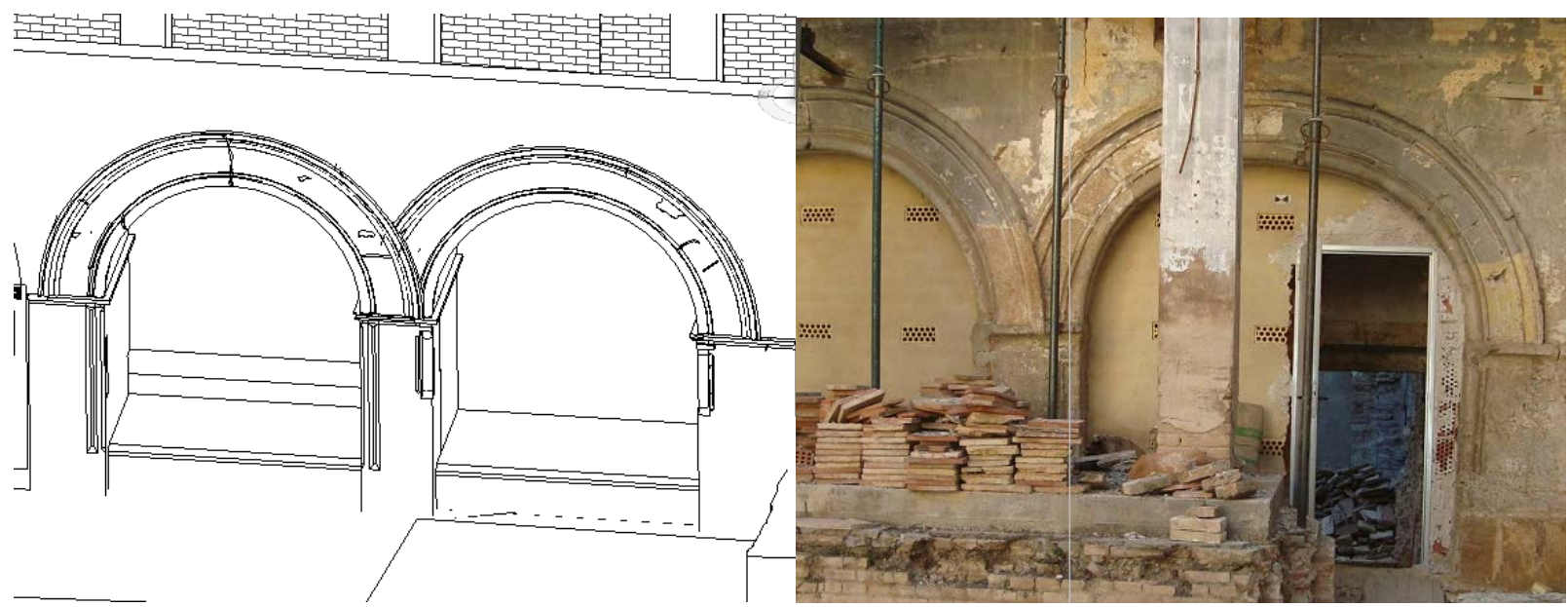

631

632

633

634

635

636

637

638

639

Figure 11. Representation of the features due to the changes over time in Revit, and the image of the current arches which are in the process of restoration.

The definition of the historic-constructive evolution in San Juan was carried out using BIMlegacy information, previously inserted by the archivist. The most relevant historical phases were represented in the HBIM model and documented in BIMlegacy. Five historical phases were modelled in the San Juan project: c. XIII, c. XIV, c. XVII, and c. XIX, as shown in Figure 12.

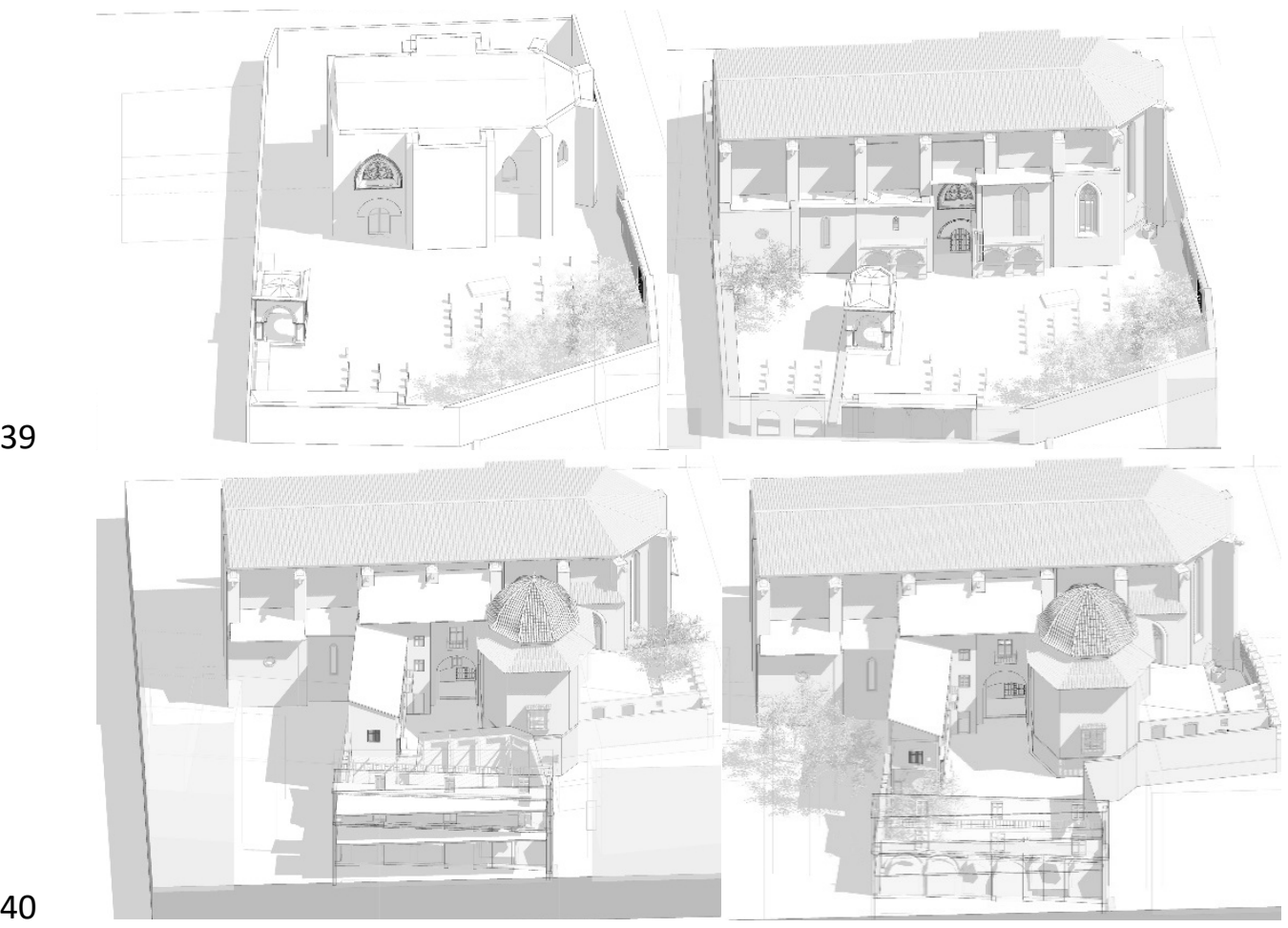

Figure 12. Five historical phases were modelled in San Juan project: c. XIII, c. XIV, c. XVII, and c. XIX 
The synchronisation of the historic and documental information with the HBIM model was constantly performed with BIMlegacy by all the stakeholders participating in the project (Figure 13).

645 Technical stakeholders and non-technical stakeholders were at different geographic locations.

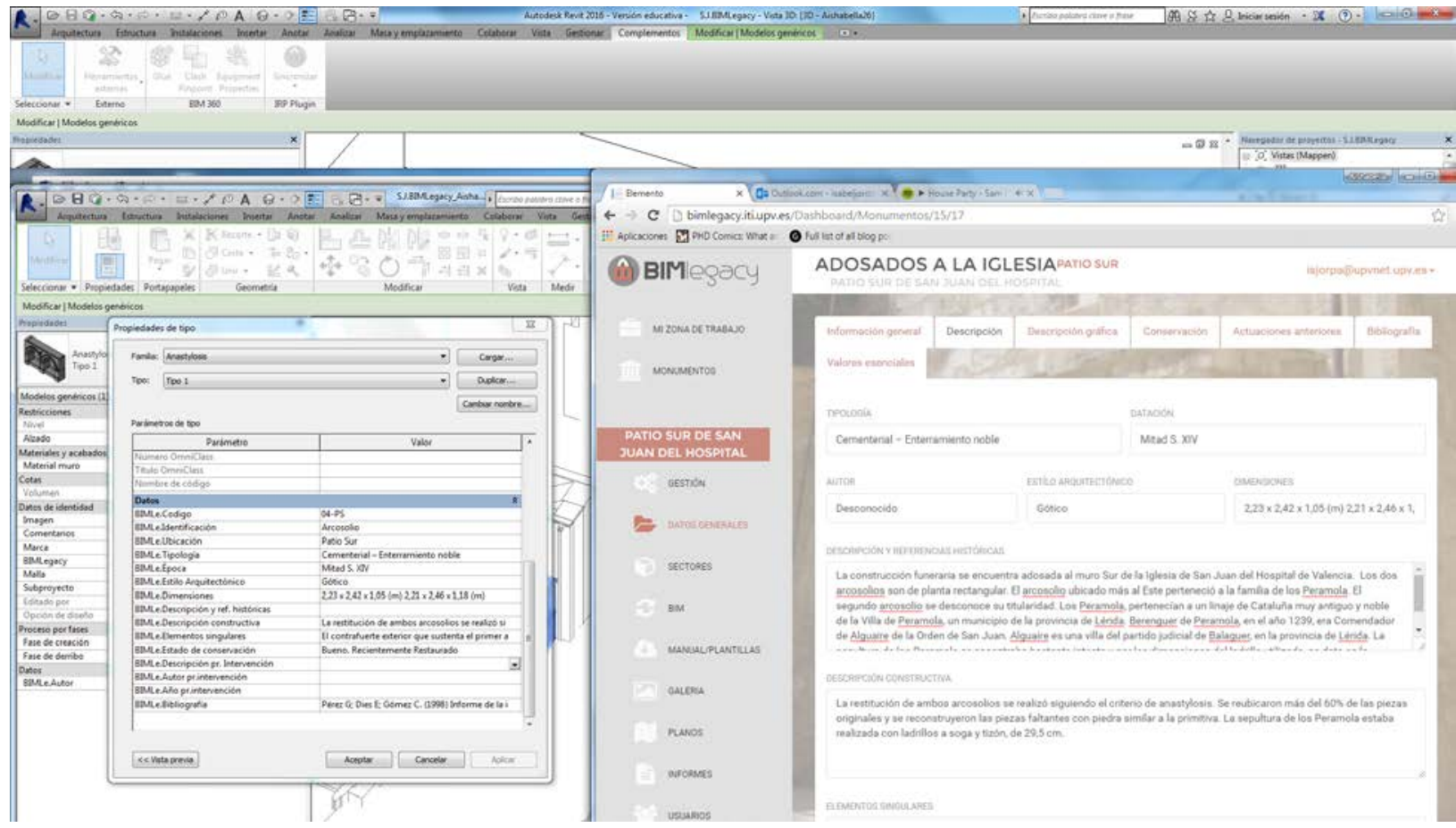

Figure 13. Synchronisation between the HBIM model data and BIMlegacy data.

The construction budget of the San Juan project was controlled using BIMlegacy and the documental database (Figure 14). The technical architect, who developed the project budget, shared information and consulted the archaeologist, the restorer and the architect to assign a realistic price to heritage activities. In previous projects, the communication between the contractor and the restorer or the archaeologist was indirect, which tends to generate a considerable budget increase.

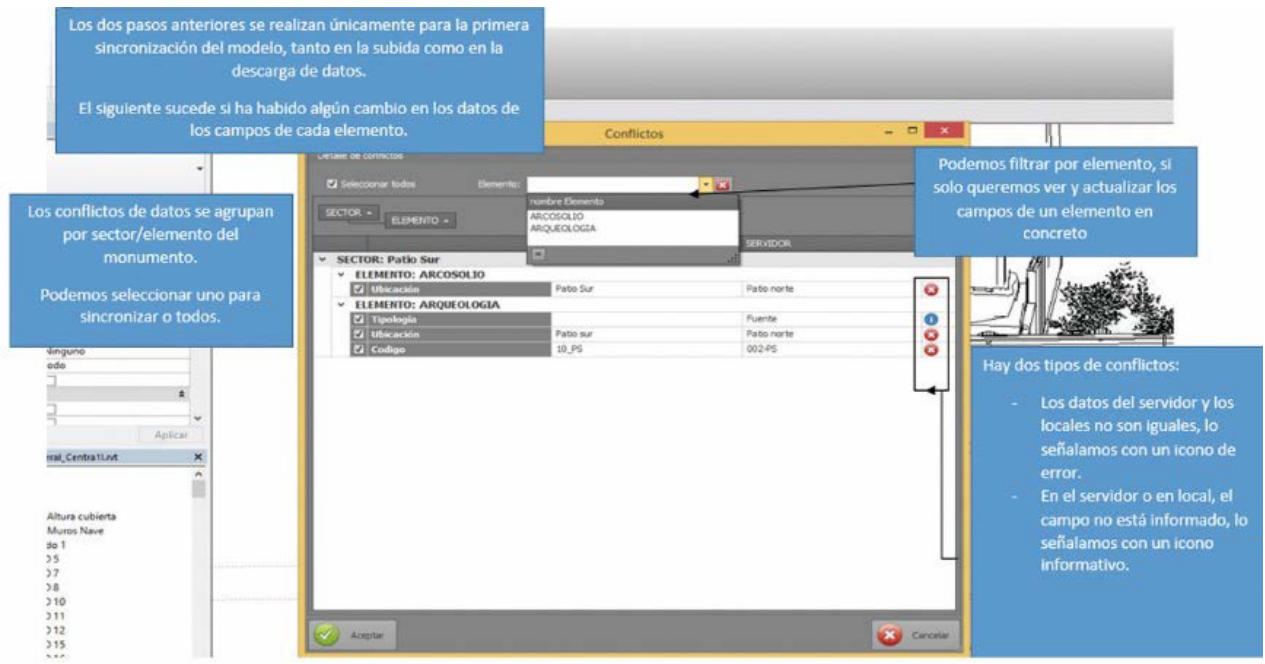

Figure 14. Plug-in that synchronises the Revit files with the documental database. 


\subsection{Contributions}

657

658

659

660

661

662

663

664

665

666

667

668

669

670

671

672

673

674

675

676

677

678

679

680

681

682

683

684

685

686

687

688

689

690

691

This paper proposed an online platform as a key benefit to assist HBIM implementation. This is the gap addressed here (Arthur et al., 2017), creating a platform which synchronises in real time non-technical stakeholders' and technical stakeholders' information through BIM. Furthermore, Simon (2006) states that the true problem of information systems resides in providing the correct filtered information to the correct people in coherence with the decisions they must make, rather than providing a large amount of untreated information. Rigorous information uploaded by professionals and which is accessible to the public is highlighted as another benefit of HBIM. The benefit of filtering the information in HBIM database systems according to the different stakeholders is that it helps them to form a decision. This is considered a contribution to knowledge because it was not highlighted in the literature before.

HBIM literature highlights concerns about the practical effectiveness of HBIM in terms of modelling complexity (Migilinskas et al., 2013), but it does not specify what are the most notable modelling issues. The analysis of the results of the case studies allowed the specification of the most notable modelling difficulties faced by heritage teams. These difficulties were modelling the wall stratigraphy, pathologies, and sculptures or complex shapes (e.g. cornices and scrollwork).

Through this research, it was found that the non-designer stakeholders require specific training to understand the technology potential; however, they should not be expected to use BIM software. Hence, a further contribution of this work is in enabling their participation in the process without specific BIM software knowledge.

BIMlegacy represents a novel CDE for heritage, which explores the best way to exchange information and improve a heritage building's workflow. This provides a contribution to practice as, according to the literature, there are no other existing HBIM platforms to manage architecture heritage (Maxwell, 2016).

The definition of HBIM roles and their permissions within a CDE is a need according to the literature (Megahed, 2015). The clear definition of the HBIM roles that participate in a HBIM platform represents a contribution.

With BIMlegacy, building owners, archivists, monument managers and government agents can easily provide inputs to the process and participate actively in the project. This is a further contribution, as it supports the improvement of the heritage workflow.

BIMlegacy has been designed to be simple and intuitive. Most existing platforms are more complex and, hence, arguably harder to implement in practice. Clear graphics and simple vocabulary are useful tools to make complex concepts easy to understand (Inyim et al., 2014). The contribution of this research resides in creating a simple and user-friendly HBIM platform, developed based on previous literature as well as existing case studies.

BIMlegacy is the first platform where rigorous information loaded by professionals and heritage experts will be accessible to the public, which is a benefit for local people interested in heritage and for 
the tourist sector. BIMlegacy prototype can highlight further ways to improve the unexplored area of tourism exploitation and BIM models (Counsell and Nagy, 2017).

Society will benefit as the rigorous information loaded by professionals and heritage experts will be accessible to the public. This dissemination of scientific findings to society is one of the recommendations of the European Commission. Cultural diffusion with BIMlegacy contributes in the long term to assure heritage's protection.

\section{Partial validation of the platform: focus group}

"The focus groups performed with the methodology explained in section 3 were recorded and transcripted into a Microsoft Word file. The transcription was analysed with the assistance of the qualitative tool analysis Nvivo 12. The qualitative metrics used in the evaluations were divided into three levels (Tzortzopoulos, 2004):

1. High-level evaluation criteria: usefulness and applicability.

2. Headline criteria: flexibility, easy to use, credibility, validity, and measurability.

3. Attributes were asked about within the questions of both focus groups and the answers were analysed to evaluate the degree of agreement on the attributes.

The qualitative process to draw conclusions out of the analysis of the participants' answers was performed by coding the transcriptions, creating cases, creating hierarchy chats, and clustering diagrams to better associate and represent ideas. The result of the analysis of the participants' answers has been presented in Table 2. It presents the attributes in the first column, which were the evaluation metrics, whereas the second column is the medium of the degree of agreement of the 11 participants of both focus groups with a scale of 1 to 5 (meaning 1 totally disagree and 5 totally agree). Each one of the attributes obtained a weighted score in base of the analysis of the transcriptions of the focus groups. The degree of agreement (a number on a scale of 1 to 5 ) was reached by weighting the number of participants that agree with the attribute. For example, when asking if BIMlegacy was generalisable to other business streams, 7 of the 11 participants agreed that it is because the obtained grade of this attributes was 3 .

\begin{tabular}{|l|c|}
\hline \multicolumn{1}{|c|}{ Attributes } & $\begin{array}{c}\text { Medium of the } \\
\text { degree of } \\
\text { agreement of the 11 } \\
\text { participants }\end{array}$ \\
\hline Generalisable to other business streams & 3 \\
\hline Generalisable to different types and sizes of projects & 4 \\
\hline Clarity on the model content & 4 \\
\hline People believe it helps heritage management & 5 \\
\hline Provides an environment where problems can be discussed & 4 \\
\hline Represents the state of the process and allows improvements & 4 \\
\hline
\end{tabular}




\begin{tabular}{|l|c|}
\hline Has it been applied in a real environment & 5 \\
\hline Performance indicators & 3 \\
\hline
\end{tabular}

Table 2. Attributes used to evaluate the focus group participants' answers.

As a result of this analysis, the conclusions of the focus group performed with interdisciplinary stakeholders were:

- The BIMlegacy prototype platform was considered useful, according to the focus group participants. The group recognised that it responds to some of the main limitations of existing platforms, as was also identified through the literature review (Antonopoulou and Bryan, 2017). The focus group participants also highlighted the need to ensure that, as a technological tool, the platform should be constantly updated.

- BIMlegacy was tested with one heritage group and one project (5. BIMlegacy implementation in a case study), but more case studies with heritage groups should be conducted to further test the platform. The platform is a novel technological tool; therefore, with further testing in future projects, its quality and utility will improve considerably.

- It was proposed to add a visor on the BIMlegacy website. The BIMlegacy platform does not incorporate a visor, instead it currently has alphanumeric fields. Some focus group participants pointed out that the platform will be more intuitive if it could have a visor of the project directly on the website (4.5. BIMlegacy user tests).

- Even though non-technical stakeholders considered that the platform functioning is intuitive and simple, it was identified that it is likely that these stakeholders would require a level of HBIM training in order to understand how the link between BIMlegacy and HBIM models works. This conclusion links with other literature conclusions (Barazzetti et al., 2015).

\section{Discussion}

As described in the literature review, there is a need for more collaborative systems in heritage projects (Zhao et al., 2015; Jiménez Cuenca, 2014), which has encouraged the creation of BIMlegacy. The results of the San Juan project indicate that BIMlegacy allows for the complete heritage documentation and improves the workflow between stakeholders, which should support, in practice, the delivery of better heritage projects. According to the interviewees, the San Juan project was developed at a higher standard than other recent projects thanks to the adoption of the BIMlegacy as a work platform. During the first two months, the San Juan project tasks developed with BIMlegacy took longer than in previous projects. However, once the stakeholders became familiarised with HBIM, the productivity increased considerably.

According to the literature, the use of BIM platforms assists higher productivity in projects as stakeholders' information can be synchronised and easily shared (Lee et al., 2017). The use of BIMlegacy can enable the synchronisation of the information in real time, a fact that accelerated the response time 
of the involved stakeholders. In the San Juan project, the stakeholders could synchronise and unify the information in real time due to the use of BIMlegacy.

Issues in modelling complex heritage structures are described in the literature (Kassem et al., 2014). In San Juan, the collaboration between historians, archaeologist, and architects was essential in order to build a coherent evolution hypothesis of the building. There were uncertainties of how the building did evolve between c. XII to c. XIII. The unification of the historic information in BIMlegacy with the archaeological modelling helped the team to create a coherent evolution hypothesis of the building between these centuries. Those stakeholders discussed the possible evolution hypothesis (a common term in the heritage community to address the changes in the structure over time) through BIMlegacy, and the architect then modelled the evolution following the archaeologist's subproject with all the archaeologic remains. Thus, the historian was involved in the process even though he was not involved in the modelling.

Previously described HBIM models do not include historic and archaeological documentation (Dore and Murphy, 2017), as only maintenance information is recorded (Ilter and Ergen, 2015). BIMlegacy takes into consideration heritage documentation when creating the website where the historian, art historian and documentarist could fully document the monuments. The San Juan project was totally documented and the historic information, included in the BIMlegacy workspace, was synchronised with the architectonic information and added in the HBIM model.

Heritage projects involve diverse stakeholders who traditionally work independently, which leads to rework and the loss of information. HBIM has not addressed these inefficiencies as various stakeholders were not able to be directly involved in previous research (Gurevich et al., 2017). BIM platforms emerged to unify and synchronise stakeholders' information. The level of collaboration between different stakeholders was higher in this project carried out with BIMlegacy than in previous, traditionally based projects in San Juan. Those previous projects included mistakes, e.g. inaccuracy between the architecture survey and the archaeological survey. With BIMlegacy, the historian and the archaeologist were working actively together and checking the coherence of the architectonic and archaeological models. Also, the San Juan building manager, who is playing the role of owner, could participate actively in the project. He reviewed the project, and the 3D models helped him to understand and visualise how the building would look after the construction works. Everything was consciously approved by the property before the construction, which is believed to have supported the project productivity, as previous research has also indicated (Sackey et al., 2014), and as guides and protocols suggest (Royal Institute of British Architects, RIBA., 2016).

The literature suggested that the budget estimates in heritage projects are very unstable (Dainty et al., 2017). Controlling the construction budget is easier and more accurate when using BIM platforms since measurements are more precise (Lee et al., 2017) and construction operations become more specific (Jeong et al., 2016). The construction budget of San Juan was controlled with higher accuracy using BIMlegacy thanks to the real interaction between the contractor and the archaeologist, the restorer and the architect, which allows the contractor to assign a realistic price to heritage budget activities. In previous projects, the communication between the contractor and the restorer or the archaeologist was indirect, but BIMlegacy brought them together. 


\subsection{Conclusions}

BIMlegacy synchronises the information of HBIM models with the BIMlegacy workspace information without latency. As such, it addresses issues that the state-of-the-art HBIM highlights: lack of historic documentation and difficulties in synchronising the diverse stakeholders' information (Dore and Murphy, 2017). It does not address issues regarding the difficulty of modelling historic structures with HBIM; however, it allows non-technical stakeholders to participate within the HBIM process without having to model in BIM.

The SQLServer of BIMlegacy archives information in the cloud, allowing for collaboration between stakeholders who are in different geographic locations. The information received from all stakeholders is archived in one single database, facilitating the future compilation of information necessary to perform a successful maintenance. The responsive design of BIMlegacy allows its use in mobile devices, such as tablets or cell phones, thus helping the user mobility. This should help in its future adoption.

The website allows the consultation and insertion of information for those stakeholders who are not familiar with BIM software. BIMlegacy now connects the innovative HBIM methodology with the traditional registration tools since an exhaustive study of historic databases was previously performed.

The representation of the historical and constructive evolutions, with all their data linked in BIMlegacy on a single model, has achieved very good results in the San Juan project. BIMlegacy helps to order and unify the crowd of constructive phases that the historic buildings used to accumulate and which generated a great deal of dispersed information.

The benefits of its adoption in the San Juan project were the reduction of project duration and the improvement in the project quality due to the accuracy of the data synchronised within BIMlegacy, as well as the non-duplication of information.

\subsection{Limitations and future research}

The BIMlegacy prototype should be tested in more heritage projects and with more stakeholders in order to keep improving it in terms of possible software functioning in various devices and to improve the usability of the website. BIMlegacy does not solve difficulties related to modelling historic structures, as the investigation focused on information management. The geometric modelling is time consuming and costly, as it reproduces the original constructive process and all the parameters need to be defined. HBIM modellers should have a high level of software knowledge to be able to model historic buildings. Further research should focus on developing software to simplify the modelling of complex structures with HBIM and create standardised families to help HBIM modellers.

The BIMlegacy website can be synchronised just with Revit files, but it is very important to generate software that can work with open BIM formats. The website interface is within the reach of all users, but it can be expensive to buy Revit licenses. For later versions, BIMlegacy will be developed to hold IFCs files. Also, LOD levels of definition will be scalable to represent the exact information of each type of user. 
Working with some of the technologies that BIMlegacy promotes requires expensive software and hardware. For example, point clouds require specific expensive programs and powerful computers in terms of RAM - the memory or information storage in a computer that is used to store running programs and data for the programs. This should be at least 16GB. Further research should study software and systems to light HBIM models and point clouds.

\section{Acknowledgments}

The communication deals with the first results achieved in the development of the research project entitled: The Design of a Database, Management Model for the Information and Knowledge of Architectural Heritage; HAR2013-41614-R, subsidised by the Spanish Ministry of Economy and Competitiveness through the National Programme for Research Aimed at the Challenges of Society. Ms Elena Salvador García and Mr Ruben March Oliver actively contributed to this project as members of the research team.

\section{References}

1. Afsari, K., Eastman, C.M. and Shelden, D.R. (2016) 'Cloud-based BIM data transmission: current status and challenges', 2016 Proceedings of the 33rd International Symposium on Automation and Robotics in Construction (ISARC 2016), Auburn, AL, USA, Pp. 1073-1080. Available at: https://doi.org/10.22260/ISARC2016/0129

2. Antonopoulou, S. and Bryan, P. (2017), BIM for Heritage: Developing a Historic Building Information. Ed. Historic England: Swindon. ISBN 1848024878. Available at: https://historicengland.org.uk/images-books/publications/bim-for-heritage/ (accessed 03/16/2019).

3. Arayici, Y., Counsell, J., Mahdjoubi, L., Nagy, G.A., Dweidar, K. and Hawas, S. (Ed.) (2017), Heritage Building Information Modelling. Taylor \& Francis: Routledge (ISBN 1317239768).

4. Arthur, S., Li, H. and Lark, R. (2017), 'A Collaborative Unified Computing Platform for Building Information Modelling (BIM)', Working Conference on Virtual Enterprise, Camarinha-Matos, Afsarmanesh et al. (Ed.), Vicenza, Italy, Vol. 506, pp. 63-73. DOI 10.1007/978-3-319-65151-4_6.

5. Barazzetti, L., Banfi, F., Brumana, R., Gusmeroli, G., Previtali, M. and Schiantarelli, G. (2015), "Cloud-to-BIM-to-FEM: Structural simulation with accurate historic BIM from laser scans", Simulation Modelling Practice and Theory, Vol. 57, pp. 71-87. DOI 10.1016/j.simpat.2015.06.004.

6. Brumana, R., Oreni, D., Raimondi, A., Georgopoulos, A. and Bregianni, A. (2013), 'From survey to HBIM for documentation, dissemination and management of built heritage: The case study of St. Maria in Scaria d'Intelvi', 2013 Digital Heritage International Congress (Digital Heritage) 28 Oct.1 Nov. 2013, Marseille, France, Vol. 1: IEEE (ISBN 1479931705).

7. Building SMART Spanish Chapter (2014), Guía de Usuarios BIM [BIM user guide]. Available at: https://www.buildingsmart.es/recursos/gu\%C3\%ADas-ubim/ (accessed 3 June 2019). 
8. Camarinha-Matos, L.M., Afsarmanesh, H., Fornasiero, R., Arthur, S., Li, H. and Lark, R. (Ed.) (2017), 'Collaboration in a Data-Rich World', 18th IFIP WG 5.5 Working Conference on Virtual Enterprises, PRO-VE 2017, Vicenza, Italy, September 18-20, 2017 Springer International Publishing (ISBN 9783-319-65151-4).

9. Council, C.I. (2013), Building Information Model (BIM) Protocol-Standard Protocol for use in projects using Building Information Models, CIC. Available at: http://cic.org.uk/admin/resources/bim-protocol2nd-edition-1.pdf (accessed 3 June 2019).

10. Counsell, J. and Nagy, G. (Eds.) (2017), 'Participatory sensing for community engagement with HBIM: Heritage building Information Modelling', Heritage Building Information Modelling. Taylor \& Francis: Routledge. Chapter 17. (ISBN 1317239768).

11. Dainty, A., Leiringer, R., Fernie, S. and Harty, C. (2017), "BIM and the small construction firm: a critical perspective", Building Research \& Information, Vol. 45 No.6, pp. 696-709. DOI 10.1080/09613218.2017.1293940.

12. Department for Communities and Local Government of United Kingdom (2012), "Annex 2: Glossary, National Planning Policy Framework", Ministry of Housing, Communities \& Local Government. Available at: https://www.gov.uk/guidance/national-planning-policyframework/annex-2-glossary (accessed 3 June 2019).

13. Dore, C. and Murphy, M. (2017), "Current State of the art Historic Building Information Modelling", ISPRS - International Archives of the Photogrammetry, Remote Sensing and Spatial Information Sciences, XLII-2/W5, №. 42. DOI 10.5194/isprs-archives-XLII-2-W5-185-2017.

14. Du, J., Zou, Z., Shi, Y. and Zhao, D. (2018), "Zero latency: Real-time synchronization of BIM data in virtual reality for collaborative decision-making", Automation in Construction, Vol. 85, pp. 51-64. DOI 10.1016/j.autcon.2017.10.009.

15. Eppich, R. and Chabbi (2011), "Recording, Documentation, and Management for the Conservation of Heritage Places", Volume 1: Guiding Principles. By Letellier, R., Schmid, W. and Leblanc, F. Volume 2: Illustrated Examples. Edited by R. Eppich and A. Chabbi. Donhead, Shaftesbury, UK, 2011 (revised edition). ISBN 978187339494. Available at: http://hdl.handle.net/10020/gci_pubs/recordim (accessed 3 June 2019).

16. European Commission, (2020) “Horizon 2020", European Union. Available at: https://ec.europa.eu/programmes/horizon2020/en/h2020-sections-projects (accessed 5 May 2018).

17. Fai, S., Graham, K., Duckworth, T., Wood, N. and Attar, R. (2011), 'Building Information Modelling and Heritage Documentation', Conference: XXIII CIPA International Symposium, 12th- 16th September, Prague, Czech Republic (ISBN 978-80-01-04885-6).

18. Faulí, J. (2008), “Composició i continuïtat en les columnes i voltes de les naus del Temple Expiatori de la Sagrada Família: descripció del sistema geomètric i del procés de definició del projecte des de l'anàlisi i interpretació del projecte d'Antoni Gaudí fins a la construcció". [Composition and continuation of the colums and vaults of the Sagrada Familia Expiatori Temple: description of the 
system]", Doctoral Thesis, Barcelona. Available at: https://books.google.es/books/about/Composici\%C3\%B3_i_continu\%C3\%AFtat_en_les_column. html?id=18PCMwEACAAJ\&redir_esc=y (accessed 3 June 2019).

905

906

907

908

909

910

19. Garagnani, S., Gaucci, A. and Govi, E. (2016), "Archaeobim: dallo scavo al Building Information Modeling di una struttura sepolta. II caso del tempio Tuscanico di uni Amarzabotto. [Archaeobim: from the excavation to the Building Information Modeling of a buried structure. The case of the Tuscanico di uni Amarzabotto temple]", Archeologia e Calcolatori, No. 27, 2016, 251-270, available at: http://eprints.bice.rm.cnr.it/16008/1/13_Garagnani_et_al.pdf (accessed 28 February 2018).

20. Gazzola, P., Leimare, R., Bassegoda-Nonell, J., Benavente, L., Daifuku, H., Vrieze, P.L. de, Langberg, H. and Matteucci, M. (1964), "International Charter for the Conservation and Restoration of Monuments and Sites", ICOMOS, World Heritage Committee. Available at: https://www.icomos.org/charters/venice_e.pdf (accessed 3 June 2019).

21. Gerçek, B., Tokdemir, O.B., Illal, M.E. and Günaydın, H.M. (2017), "BIM execution process of construction companies for building projects". Resilient Structures and Sustainable Construction Edited by Pellicer, E., Adam, J. M., Yepes, V., Singh, A., and Yazdani S. (Ed.). ISEC Press. (ISBN 9780-9960437-4-8).

22. Getty Conservation Institute (2019), "Arches Project" Getty Conservation Institute and World Monuments Fund.

Available

at: https://www.getty.edu/conservation/our_projects/field_projects/arches/arches_overview.html (accessed 2 June 2019).

23. Gibbs, A. (1997), "Focus groups". Social Research Update. University of Surrey, Guildford, England: Department of Sociology. Available at: http://sru.soc.surrey.ac.uk/SRU19.html (accessed 4 June 2019).

24. González-Varas Ibáñez, I. (1999), Conservación de bienes culturales: Teoría, historia, principios y normas [Conservation of cultural property: Theory, history, principles and norms]. Manuales arte Cátedra: Ed. Cátedra, Madrid (ISBN 8437617219).

25. Green, A. and Dixon, J. (2016), "Standing buildings and built heritage", Post-Medieval Archaeology, Vol. 50 No. 1, pp. 121-133. DOI 10.1080/00794236.2016.1169492.

26. Grilo, A. and Jardim-Goncalves, R. (2010), "Value proposition on interoperability of BIM and collaborative working environments", Automation in Construction, Vol. 19 No. 5, pp. 522-530. DOI 10.1016/j.autcon.2009.11.003.

27. Grover, R. and Froese, T.M. (2016), "Knowledge management in construction using a SocioBIM platform: A case study of AYO smart home project", Procedia Engineering, Vol. 145, pp. 12831290. DOI 10.1016/j.proeng.2016.04.165.

28. Gurevich, U., Sacks, R. and Shrestha, P. (2017), "BIM adoption by public facility agencies: impacts on occupant value", Building Research \& Information, Vol. 45 No.6, pp. 610-630. DOI 10.1080/09613218.2017.1289029. 
29. Holmström, J., Ketokivi, M. and Hameri, A.-P. (2009), "Bridging practice and theory: A design science approach", Decision Sciences, Vol.40 No.1, pp. 65-87. DOI 10.1111/j.15405915.2008.00221.x.

30. Howell, S., Rezgui, Y. and Beach, T. (2017), "Integrating building and urban semantics to empower smart water solutions", Automation in Construction, Vol.81, pp. 434-448. DOI 10.1016/j.autcon.2017.02.004.

31. Ilter, D. and Ergen, E. (2015), "BIM for building refurbishment and maintenance: current status and research directions", Structural Survey, Vol. 33 No. 3, pp. 228-256. DOI 10.1108/SS-02-20150008 .

32. Inyim, P., Rivera, J. and Zhu, Y. (2014), "Integration of building information modeling and economic and environmental impact analysis to support sustainable building design", Journal of Management in Engineering, Vol.31 No.1, A4014002. DOI 10.1061/(ASCE)ME.19435479.0000308.

33. Jeong, W., Chang, S., Son, J. and Yi, J.-S. (2016), "BIM-integrated construction operation simulation for just-in-time production management", Sustainability, Vol. 8 No. 11, p. 1106. DOI $10.3390 /$ su8111106.

34. Jiménez Cuenca, C. (2014), Los Planes Nacionales de catedrales y de abadías, monasterios y conventos [The National Plans of cathedrals and abbeys, monasteries and convents], AADIPA: COAC, Madrid, Spain, available at: http://hdl.handle.net/2099/16411 (accessed 5 July 2019).

35. Kassem, M., Iqbal, N., Kelly, G., Lockley, S. and Dawood, N. (2014), "Building information modelling: protocols for collaborative design processes", Journal of Information Technology in Construction (ITcon), Vol.19, pp. 126-149, available at: https://www.researchgate.net/publication/288578062_Building_information_modelling_Protoc ols_for_collaborative_design_processes (accessed 5 July 2019).

36. Kempton, J. (2006), "Can lean thinking apply to the repair and refurbishment of properties in the registered social landlord sector?", Structural Survey, Vol. 24 No.3, pp. 201-211. DOI 10.1108/02630800610678850.

37. Lee, J., Park, Y.-J., Choi, C.-H. and Han, C.-H. (2017), "BIM-assisted labor productivity measurement method for structural formwork", Automation in Construction, Vol.84, pp. 121-132. DOI 10.1016/j.autcon.2017.08.009.

38. Li, C.Z., Xue, F., Li, X., Hong, J. and Shen, G.Q. (2018), "An Internet of Things-enabled BIM platform for on-site assembly services in prefabricated construction", Automation in Construction, Vol. 89, pp. 146-161. DOI 10.1016/j.autcon.2018.01.001.

39. Maxwell, I. (2014), "Integrating Digital Technologies in Support of Historic Building Information Modelling Bim4conservation: BIM4Conservation(HBIM)", Conference on Training in Architectural Conservation (COTAC). Available at: http://www. cotac. org. uk/docs/COTAC-HBIM-Report-FinalA-21-April-2014-2-small. pdf (accessed 14 June 2015). 
40. Maxwell, I. (2016), "COTAC BIM4C Integrating HBIM Framework Report", Council on Training in Architectural Conservation (COTAC). COTAC. Available at: https://cotac.global/resources/HBIMFramework-Part-1-February-2016.pdf (accessed 23 May 2016).

41. Megahed, N.A. (2015), "Towards a theoretical framework for HBIM approach in historic preservation and management", ArchNet-IJAR: International Journal of Architectural Research, Vol. 9 No. 3, p. 130. DOI 10.26687/archnet-ijar.v9i3.737.

42. Migilinskas, D., Popov, V., Juocevicius, V. and Ustinovichius, L. (2013), "The benefits, obstacles and problems of practical BIM implementation”, Procedia Engineering, Vol. 57, pp. 767-774. DOI 10.1016/j.proeng.2013.04.097.

43. Murphy, M., McGovern, E. and Pavia, S. (2009), "Historic Building Information Modelling (HBIM)", Structural Survey, Vol. 27 No. 4, pp. 311-327. DOI 10.1108/02630800910985108.

44. Naeyer, A. de, Arroyo, S. and Blanco, J. (2000), Krakow Charter 2000: principles for conservation and restoration of built heritage, Krakow, Polan: Bureau Krakow 2000. Available at: http://smartheritage.com/wp-content/uploads/2015/03/KRAKOV-CHARTER-2000.pdf (accessed 3 June 2018).

45. Oreni, D., Brumana, R., Della Torre, S., Banfi, F. and Previtali, M. (2014), "Survey turned into HBIM: the restoration and the work involved concerning the Basilica di Collemaggio after the earthquake (L'Aquila)", ISPRS Annals of the Photogrammetry, Remote Sensing and Spatial Information Sciences, Vol. 2 No. 5, p. 267. DOI 10.5194/isprsannals-II-5-267-2014.

46. Peffers, K., Tuunanen, T., Rothenberger, M.A. and Chatterjee, S. (2007), “A design science research methodology for information systems research", Journal of Management Information Systems, Vol. 24 No. 3, pp. 45-77. DOI 10.2753/MIS0742-1222240302.

47. Perng, Y.-H., Hsia, Y.-P. and Lu, H.-J. (2007), “A Service Quality Improvement Dynamic Decision Support System for Refurbishment Contractors", Total Quality Management \& Business Excellence, Vol. 18 No. 7, pp. 731-749. DOI 10.1080/14783360701349716.

48. PetroBIM and Armisien, A. (2014), PetroBIM, http://petrobim.com/. Available at: http://petrobim.com/ (accessed 4 June 2019).

49. Quattrini, R., Malinverni, E.S., Clini, P., Nespeca, R. and Orlietti, E. (2015), “From TLS to HBIM. High quality semantically-aware 3D modeling of complex architecture", International Archives of the Photogrammetry, Remote Sensing \& Spatial Information Sciences, Vol. 40 No. 5, p. 367. DOI 10.5194/isprsarchives-XL-5-W4-367-2015.

50. Royal Institute of British Architects, RIBA. (Ed.) (2016), “NBS International BIM Report 2016. Attitudes towards governments and BIM", RIBA Enterprise Ltd: NBS. Available at: https://www.thenbs.com/knowledge/nbs-international-bim-report-2016 (accessed 4 June 2019).

51. Sackey, E., Tuuli, M. and Dainty, A. (2014), "Sociotechnical systems approach to BIM implementation in a multidisciplinary construction context", Journal of Management in Engineering, Vol. 31 No. 1, A4014005. DOI 10.1061/(ASCE)ME.1943-5479.0000303. 
1014

1015

1016

1017

1018

1019

1020

1021

1022

1023

1024

1025

1026

1027

1028

1029

1030

1031

1032

1033

1034

1035

1036

1037

1038

1039

1040

1041

1042

1043
52. Salvador-García, E., García-Valldecabres, J. and Blasco, Viñals, M.J. (2018), "The Use Of Hbim Models As A Tool For Dissemination And Public Use Management Of Historical Architecture: A Review", Building Information Systems in the Construction Industry, p. 101. DOI 10.2495/SDP-V13N1-96-107.

53. Spain is Culture (2018), "España es cultura: portal oficial de la cultura de España [Spain is culture: oficial website of the Spanish culture]", Ministry of Culture and Sport: S.A.M.P. (SEGITTUR) available at: http://www.xn--espaaescultura-tnb.es/ (accessed 9 August 2018).

54. Standard I. S.O. (2010), "ISO 29481-1: 2010 (E), Building Information Modeling-Information Delivery Manual-Part 1: Methodology and Format (2010)", ISO, Technical Committee : ISO/TC 59/SC 13 Organization and digitization of information about buildings and civil engineering works, including building information modelling (BIM). Available at: https://www.iso.org/standard/45501.html (accessed 4 June 2019).

55. Teo, M.M.M. and Loosemore, M. (2001), "A theory of waste behaviour in the construction industry", Construction Management \& Economics, Vol.19 No.7, pp. 741-751. DOI 10.1080/01446190110067037.

56. Tzortzopoulos, P. (2004), "The design and implementation of product development process models in construction companies. Doctoral Thesis", University of Salford, 2004. Available at: https://www.researchgate.net/profile/Patricia_Tzortzopoulos/publication/24077993_An_invest igation_on_the_implementation_of_product_development_process_models_in_construction_c ompanies/links/09e4150c06002b03e4000000/An-investigation-on-the-implementation-ofproduct-development-process-models-in-construction-companies.pdf (accessed 25 June 2019).

57. Visual Computing Laboratory - ISTI - CNR initiative (2019), “3DHOP - Home”, Visual Computing Laboratory - ISTI - CNR initiative. Available at: http://vcg.isti.cnr.it/3dhop/ (accessed 2 June 2019).

58. Volk, R., Stengel, J. and Schultmann, F. (2014), "Building Information Modeling (BIM) for existing buildings-Literature review and future needs", Automation in Construction, Vol. 38, pp. 109127. DOI 10.1016/j.autcon.2013.10.023.

59. Zhao, D., McCoy, A.P., Bulbul, T., Fiori, C. and Nikkhoo, P. (2015), "Building collaborative construction skills through BIM-integrated learning environment", International Journal of Construction Education and Research, Vol.11 No.2, pp. 97-120. DOI 10.1080/15578771.2014.986251. 